\title{
Morphological and functional changes in TRPM8-expressing corneal cold thermoreceptor neurons during aging and their impact on tearing in mice
}

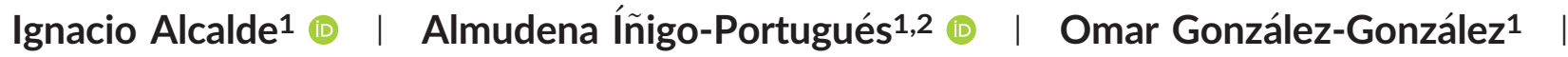 \\ Laura Almaraz $^{2}$ | Enol Artime ${ }^{1}$ | Cruz Morenilla-Palao ${ }^{2}$ | Juana Gallar ${ }^{2}$ (i) | \\ Félix Viana ${ }^{2}$ (1) | Jesús Merayo-Lloves ${ }^{1}$ () | Carlos Belmonte ${ }^{1,2}$ (1)
}

${ }^{1}$ Instituto Universitario Fernández-Vega, Universidad de Oviedo \& Fundación de Investigación Oftalmológica, Oviedo, Spain

${ }^{2}$ Instituto de Neurociencias, Universidad Miguel Hernández-CSIC, San Juan de Alicante, Spain

\section{Correspondence}

Carlos Belmonte, Instituto de

Neurociencias, UMH-CSIC, Avenida Santiago Ramon y Cajal, 2, 03550 San Juan de Alicante.

Email: carlos.belmonte@umh.es

\section{Funding information}

Ministerio de Economía, Industria y Competitividad, Grant/Award Number: SAF2014-54518-C3-1-R, SAF2014-54518C3-2-R, SAF2016-77233-R, SAF201783674-C2-1-R, SAF2017-83674-C2-2-R, SEV-2013-0317; Consejería de Economía y Empleo, Grant/Award Number: FC-15GRUPIN14-141

\begin{abstract}
Morphological and functional alterations of peripheral somatosensory neurons during the aging process lead to a decline of somatosensory perception. Here, we analyze the changes occurring with aging in trigeminal ganglion (TG), TRPM8-expressing cold thermoreceptor neurons innervating the mouse cornea, which participate in the regulation of basal tearing and blinking and have been implicated in the pathogenesis of dry eye disease (DED). TG cell bodies and axonal branches were examined in a mouse line (TRPM8 ${ }^{\mathrm{BAC}}$-EYFP) expressing a fluorescent reporter. In 3 months old animals, about $50 \%$ of TG cold thermoreceptor neurons were intensely fluorescent, likely providing strongly fluorescent axons and complex corneal nerve terminals with ongoing activity at $34^{\circ} \mathrm{C}$ and low-threshold, robust responses to cooling. The remaining TRPM $8^{+}$corneal axons were weakly fluorescent with nonbeaded axons, sparsely ramified nerve terminals, and exhibited a low-firing rate at $34^{\circ} \mathrm{C}$, responding moderately to cooling pulses as do weakly fluorescent TG neurons. In aged (24 months) mice, the number of weakly fluorescent TG neurons was strikingly high while the morphology of $\mathrm{TRPM}^{+}$corneal axons changed drastically; $89 \%$ were weakly fluorescent, unbranched, and often ending in the basal epithelium. Functionally, $72.5 \%$ of aged cold terminals responded as those of young animals, but $27.5 \%$ exhibited very low-background activity and abnormal responsiveness to cooling pulses. These morpho-functional changes develop in paralle with an enhancement of tear's basal flow and osmolarity, suggesting that the aberrant sensory inflow to the brain from impaired peripheral cold thermoreceptors contributes to age-induced abnormal tearing and to the high incidence of DED in elderly people.
\end{abstract}

\section{KEYWORDS}

aging, cold thermoreceptors, dry eye, pain, tearing, trigeminal ganglion, RRID: AB_221569, RRID: AB_300798, RRID: AB_291637, RRID: AB_477272, RRID: AB_90725, RRID: AB_310180, RRID: AB_725807, RRID: AB_2313606, RRID: AB_2534095, RRID: AB_2576217, RRID: AB_142924, RRID: AB_142540, RRID: AB_2313921
Ignacio Alcalde, Almudena Î́nigo-Portugués, and Omar González-González contributed equally to this study.

\section{1 | INTRODUCTION}

Wetness of the ocular surface is maintained by the tear film, a complex entity that is composed of a muco-aqueous fluid layer, isolated from air

This is an open access article under the terms of the Creative Commons Attribution-NonCommercial-NoDerivs License, which permits use and distribution in any medium, provided the original work is properly cited, the use is non-commercial and no modifications or adaptations are made.

(c) 2018 Wiley Periodicals, Inc. 
by a superficial lipid layer (Stern et al., 2004). Aqueous tear fluid is continuously produced by the lacrimal glands at a mean basal rate of $\sim 2$ $\mu \mathrm{L} \cdot \mathrm{min}^{-1}$ in humans (basal tearing) (Furukawa \& Polse, 1978). Basal, continuous tear production is tonically modulated by peripheral sensory input from the eye surface (Lamberts et al., 1979; Robbins et al., 2012). Recent evidence suggests a prominent role for ocular cold thermoreceptors in the regulation of basal tear production. When activity of cold thermoreceptors is silenced in mice by genetic deletion of TRPM8, the ion channel conferring them cold sensitivity (McKemy et al., 2002; Peier et al., 2002), basal tear flow is markedly reduced (Parra et al., 2010). Likewise, warming the ocular surface in humans, which decreases cold thermoreceptor sensory input, reduces basal tearing while cooling increases tear secretion (Acosta et al., 2004; Parra et al., 2010). The majority of cold thermoreceptors innervating the ocular surface display a continuous ongoing firing at normal eye surface temperatures of $33-34^{\circ} \mathrm{C}$, that is augmented or reduced by cooling or heating, respectively (Brock et al., 2001; Gallar et al., 1993; GonzálezGonzález et al., 2017). Together, these observations support the hypothesis that sensory inflow from cold thermoreceptors, which is increased by evaporation-induced cooling, modulates tear flow, and possibly also contributes to conscious dryness sensations of the eye surface (Belmonte \& Gallar, 2011; Belmonte et al., 2015, 2017; González-González et al., 2017; Hirata \& Oshinsky, 2012; Kovács et al., 2016).

Dry eye disease (DED) is a multifactorial disease defined by an inability to produce a tear film of volume and/or quality adequate to allow proper lubrication and protection of the corneal surface. It is accompanied by discomfort or pain, increased tear osmolarity, disturbed visual acuity, inflammation, and an elevated susceptibility to infection. DED is the most common ocular disease, affecting $>5 \%$ of the world's population (Craig et al., 2017). Noteworthy, DED incidence increases sharply with age, reaching prevalence values of $25-30 \%$ in individuals over sixty (Craig et al., 2017).

At the eye surface, aging causes a variety of morphological and functional changes (Gipson, 2013), including a reduced mechanical sensitivity and a decrease in the number of subbasal axons and nerve terminals in the corneal epithelium (Acosta et al., 2006; Dvorscak \& Marfurt, 2008). Accordingly, a relationship between age-dependent reduction of eye innervation and disturbed tear production has been repeatedly suggested (Acosta et al., 2006; Belmonte et al., 2015; Hirata \& Meng, 2010; Hirata \& Oshinsky, 2012; Meng \& Kurose, 2013). Aging affects the structure and performance of peripheral sensory nerves in all tissues (Bergman \& Ulfhake, 1998; Wang \& Albers, 2009). Corneal nerves represent an ideal experimental model to study the aging process in sensory nerves due to their accessibility, ordered distribution, and well-established function. Furthermore, the noted dependence of basal tearing rate on cold thermoreceptor input in mice (Parra et al., 2010) opens the possibility that age-induced disturbances in this subpopulation of sensory fibers are linked to the sensory and tearing alterations observed in patients with DED.

In the present work, we used transgenic TRPM8 ${ }^{\mathrm{BAC}}$-EYFP mice (Morenilla-Palao et al., 2014; Parra et al., 2010) in which TRPM8expressing cold thermoreceptor neurons are intrinsically fluorescent, to investigate the effects of aging on the morphology and function of the cell bodies and sensory nerve terminals of this population of somatosensory neurons. We also determined whether the changes detected for cold thermoreceptor neurons are related with the changes in basal tearing flow that occur with aging.

\section{2 | METHODS}

\section{1 | Experimental animals}

Experiments were conducted in accordance with the ARVO Statement for the Use of Animals in Ophthalmic and Vision Research, the European Union Directive (2010/63/EU) and the Spanish regulations on the protection of animals used for research (RD 53/2013), and followed a protocol approved and supervised by the Ethics Committee of the Universities of Oviedo and Miguel Hernandez.

A total of 60 TRPM8 ${ }^{\mathrm{BAC}}$-EYFP and $105 \mathrm{C} 57 \mathrm{BL} / 6$ mice of 3 months (3M) and 24 months (24M) of both sexes were used. Animals were housed conventionally in temperature- and humidity-controlled facilities with food and water available ad libitum.

\section{2 | Immunohistochemistry}

TRPM8 ${ }^{\mathrm{BAC}}$-EYFP mice were anesthetized with a mixture of ketamine (80 mg/kg; Imalgène $500^{\circledR}$, Merial; Toulouse, France) and xylazine (5 mg/kg; Rompun ${ }^{\circledR}$, Bayer, Munich, Germany) and euthanized with an overdose of intraperitoneal sodium pentobarbital (Dolethal ${ }^{\circledR}$, Vetoquinol, Lure, France). Eyes and trigeminal ganglia (TG) were carefully removed and processed, as detailed below.

\subsection{1 | Whole-mounted corneas}

ABC-peroxidase method

Eyeballs were fixed for $1 \mathrm{hr}$ at room temperature (RT) in 4\% paraformaldehyde and $0.2 \%$ picric acid in $0.1 \mathrm{M}$ phosphate buffer saline (PBS, $\mathrm{pH}$ 7.4). Corneas were dissected and washed in PBS. To increase their permeability, corneas were incubated overnight at $37^{\circ} \mathrm{C}$ in $0.01 \%$ hyaluronidase type IV-S (Sigma-Aldrich, St. Louis, MO) and 0.1\% ethylenediaminetetraacetic acid (EDTA; Sigma-Aldrich) (Marfurt et al., 2010) in $0.1 \mathrm{M}$ acetate buffer ( $\mathrm{pH}$ 6.0). Afterward, the corneas were rinsed in PBS containing $0.1 \%$ Triton X-100 (PBS-TX) and incubated for $2 \mathrm{hr}$ in blocking solution containing $1 \%$ bovine serum albumin (BSA; Vector Laboratories, Burlingame, CA) and 10\% normal goat serum (Vector Laboratories) in PBS-TX at RT. Corneas were then incubated overnight at $4^{\circ} \mathrm{C}$ with a rabbit polyclonal antibody against GFP (1:500; Molecular Probes, Eugene, OR). After rinsing with PBS-TX, corneas were incubated for $2 \mathrm{hr}$ at RT with a goat anti-rabbit IgG biotinylated secondary antibody (1:200; Vector Laboratories). After again rinsing with PBS-TX, the corneas were incubated for $2 \mathrm{hr}$ at RT in avidin-biotin-horseradish peroxidase complex (ABC reagent; Vector Laboratories). Corneas were washed with PBS-TX and incubated for $2 \mathrm{~min}$ at RT in 0.1\% diaminobenzidine (Sigma-Aldrich) and $0.03 \% \mathrm{H}_{2} \mathrm{O}_{2}$. After rinsing with $\mathrm{PBS}$, the corneas were dehydrated in graded ethanol, cleared with xylol and mounted on slides with Entellan mounting medium (Merck Millipore, Darmstadt, Germany). 


\section{Immunofluorescence}

Corneas were fixed for $2 \mathrm{hr}$ at RT in methanol and DMSO (4:1), rehydrated, and washed in PBS. They were incubated for $1 \mathrm{hr}$ in blocking solution containing 1\% BSA (Vector Laboratories) and 10\% normal goat serum (Vector Laboratories) in PBS-TX at RT. After rinsing with PBS$\mathrm{TX}$, corneas were incubated for $48 \mathrm{hr}$ at $4^{\circ} \mathrm{C}$ with the primary antibodies diluted in PBS-TX. Rabbit anti-neuronal class III $\beta$-tubulin (1:500; Covance Research Products, Berkeley, CA) and chicken anti-GFP (1:500; Abcam, Cambridge, MA) were used. After rinsing with PBS-TX, corneas were incubated for $2 \mathrm{hr}$ at RT with Alexa Fluor 594 goat antirabbit IgG and Alexa Fluor 488 goat anti-chicken IgG, respectively (1:500; Molecular Probes) in PBS, followed by incubation for $10 \mathrm{~min}$ at RT with 4', 6-diamidino-2-phenylindole (DAPI; $2 \mu \mathrm{g} / \mathrm{mL}$; Molecular Probes).

\subsection{2 | Trigeminal ganglia}

Deeply anesthetized mice, in which eyeballs were removed to use their corneas for whole mount immunostaining as described above, were perfused immediately afterward with physiological saline through the ascending aorta, followed by 15 min perfusion with 4\% paraformaldehyde and $0.2 \%$ picric acid in PBS. TG were then removed and postfixed for $1 \mathrm{hr}$ at RT in the same fixative, cryoprotected overnight at $4^{\circ} \mathrm{C}$ in $30 \%$ sucrose in PBS, embedded in OCT medium (Sakura Finetek, Torrance, $C A$ ) and rapidly frozen in liquid nitrogen. Blocks were stored at $-80^{\circ} \mathrm{C}$ until used. TG were cut on a cryostat microtome in serial $7-\mu \mathrm{m}$ thick sections and mounted on Superfrost Plus slides. Tissue sections were washed in PBS containing $0.03 \%$ Triton X-100 for 10 min and blocked for $1 \mathrm{hr}$ in PBS containing 10\% goat serum or donkey serum (depending on secondary antibodies used) at RT and incubated overnight at $4^{\circ} \mathrm{C}$ with primary antibodies diluted in blocking solution. The following rabbit polyclonal antibodies were used: anti-NF200 (1:1000, Sigma-Aldrich), anti-Peripherin (1:500, Millipore) and anti-TrkA (1:500, Millipore). In addition, goat polyclonal anti-CGRP (1:500, Abcam) was used. Sections were then washed with PBS and incubated for $2 \mathrm{hr}$ at RT with goat anti-rabbit IgG or donkey anti-goat IgG secondary antibodies conjugated to Alexa Fluor 594 (1:500, Molecular Probes) in PBS. To detect IB4 staining, sections were incubated overnight with Griffonia Simplicifolia isolectin, (GS-IB 4 Alexa Fluor 594 conjugate, 1:500; Molecular Probes) in PBS at $4^{\circ} \mathrm{C}$. Thereafter, sections were washed in PBS and incubated with DAPI for 10 min at RT. Finally, slides were coverslipped with fluorescence mounting medium (Dako, Glostrup, Denmark).

\subsection{3 | Antibody characterization}

Details of antibodies and dilutions are provided in Table 1. The antiGFP (Molecular Probes, A11122, RRID: AB_221569) is a polyclonal antibody raised in rabbit against GFP isolated directly from the jellyfish Aequorea Victoria and is an IgG fraction purified by ion-exchange chromatography. The anti-GFP (Abcam, ab13970, RRID: AB_300798) is a polyclonal antibody raised in chicken using as munogen a recombinant full-length protein corresponding to GFP from A. victoria (UniProt number P42212). The anti-tubulin $\beta$ III (Covance, PRB-435P, RRID: $A B \_291637$ ) is a polyclonal rabbit lgG (clone Poly 18020) generated against the same epitope as recognized by TUJ1 using microtubules derived from rat brain as immunogen. The epitope is located within the last $15 \mathrm{C}$-terminal residues. It was subsequently purified on a peptide affinity column. This antibody is well characterized and highly reactive to neuron specific class III $\beta$-tubulin ( $\beta$ III) but does not identify $\beta$-tubulin found in glial cells. Anti-NF200 (Sigma-Aldrich, N4142, RRID $A B 477272$ ) is a polyclonal antibody produced in rabbit using as immunogen purified neurofilament 200 from bovine spinal cord. Whole antiserum is purified to provide an IgG fraction of antiserum. Antiperipherin (Millipore, AB1530, RRID: AB_90725) is a polyclonal antibody produced in rabbit as purified serum using as immunogen electrophoretically pure trp-E-peripherin fusion protein, containing all but the $4 \mathrm{~N}$ terminal amino acids of rat peripherin. The antibody recognizes Peripherin (UniProt number P41219) and stains a $\sim 57 \mathrm{kDa}$ band cleanly and specifically and does not stain vimentin, GFAP, alphainternexin or any of the neurofilament subunits. Strong staining on rat, mouse, human, pig, and cow peripherin. Does not stain chicken, quail, or other more distantly related species which appear to lack peripherin. The anti-TrkA (Millipore, 06-574, RRID: AB_310180) is a purified polyclonal antibody $(\mathrm{IGg})$ raised in rabbit immunized with bacterially expressed purified protein corresponding to the entire extracellular domain of rat TrkA receptor. Recognizes TrkA, Mr 140 kDa (UniProt number P04629). Does not cross-react with TrkB or TrkC. The antiCGRP (Abcam, ab36001, RRID: AB_725807) is a polyclonal antibody produced in goat immunized with a synthetic peptide corresponding to rat CGRP ( $C$ terminal, VKDNFVPTNVGSEAF). The antibody reacts with whole molecule (1-37) and 23-37 fragment ( $C$ terminal).

The secondary antibody used for immunoperoxidase technique (Vector Laboratories, BA-1000, RRID: AB_2313606) is an affinity purified (chromatography), polyclonal biotynilated anti-rabbit lgG, made in goat following proprietary immunization schedules from the manufacturer. The antibody recognizes both heavy and light chains of rabbit IgG. The incubation solution contained secondary antibody to a 1:200 dilution. The following polyclonal secondary antibodies were all purchased from Molecular Probes and were used to a final dilution of 1:500. AF594-anti-rabbit (A11037, RRID: AB_2534095) is a secondary antibody raised in goat against heavy and light chains of rabbit Gamma immunoglobulins IgG and conjugated with the Alexa Fluor ${ }^{\circledR} 594$ fluorescent dye (6 fluorophore molecules per IgG molecule with ideal excitation at $594 \mathrm{~nm}$ ). AF488-anti-rabbit IgG (A11034, RRID: AB_2576217) is a secondary antibody raised in goat against heavy and light chains of chicken Gamma immunoglobulins IgG and conjugated with the Alexa Fluor ${ }^{\circledR} 488$ fluorescent dye (6 fluorophore molecules per lgG molecule with ideal excitation at $488 \mathrm{~nm}$ ). According to manufacturer's description, to minimize the cross-reactivity of goat antirabbit IgGs whole antibodies have been cross-adsorbed against bovine, goat, mouse, rat and human IgG. AF488-anti-Chicken IgY (A11039, RRID: AB_142924) is a secondary antibody raised in goat against heavy and light chains of chicken Gamma immunoglobulins IgY and conjugated with the Alexa Fluor ${ }^{\circledR} 488$ fluorescent dye (7 fluorophore molecules per IgY molecule with ideal excitation at $488 \mathrm{~nm}$ ). This goat antichicken IgY whole antibody has been purified by cross-adsorption through a column matrix containing immobilized serum proteins from potentially cross-reactive species. 
TABLE 1 Antibodies and lectins used in this study

\begin{tabular}{|c|c|c|c|}
\hline Name & Immunogen & $\begin{array}{l}\text { Manufacturer; catalog number; RRID; host } \\
\text { species; mono/polyclonal }\end{array}$ & Dilution \\
\hline \multicolumn{4}{|l|}{ Primary antibodies } \\
\hline Anti-GFP & $\begin{array}{l}\text { The GFP was isolated directly from } \\
\text { the jellyfish A. victoria }\end{array}$ & $\begin{array}{l}\text { Molecular Probes; A11122; AB_221569; rabbit; } \\
\text { polyclonal }\end{array}$ & $1: 500$ \\
\hline Anti-GFP & $\begin{array}{l}\text { Recombinant full-length protein cor- } \\
\text { responding to GFP from A. victoria }\end{array}$ & $\begin{array}{l}\text { Abcam; ab13970; AB_300798; chicken; } \\
\text { polyclonal }\end{array}$ & $1: 500$ \\
\hline Anti-tubulin $\beta$ III & Neuronal class III beta tubulin & $\begin{array}{l}\text { Covance Research Products; PRB-435P; } \\
\text { AB_291637; rabbit; polyclonal }\end{array}$ & $1: 500$ \\
\hline Anti-NF200 & $\begin{array}{l}\text { Neurofilament } 200 \text { from bovine spinal } \\
\text { cord }\end{array}$ & $\begin{array}{l}\text { Sigma Aldrich; N4142; AB_477272; rabbit; } \\
\text { polyclonal }\end{array}$ & $1: 1000$ \\
\hline Anti-peripherin & $\begin{array}{l}\text { Trp-E-peripherin fusion protein con- } \\
\text { taining all but the } 4 \mathrm{~N} \text {-terminal } \\
\text { amino acids of rat peripherin }\end{array}$ & $\begin{array}{l}\text { Millipore; AB1530; AB_90725; rabbit; } \\
\text { polyclonal }\end{array}$ & $1: 500$ \\
\hline Anti-TrkA & $\begin{array}{l}\text { Purified protein corresponding to the } \\
\text { entire extracellular domain of rat } \\
\text { TrkA receptor }\end{array}$ & $\begin{array}{l}\text { Millipore; 06-574; AB_310180; rabbit; } \\
\text { polyclonal }\end{array}$ & $1: 500$ \\
\hline Anti-CGRP & $\begin{array}{l}\text { Synthetic peptide corresponding to rat } \\
\text { CGRP (C-terminal) }\end{array}$ & Abcam; ab36001; AB_725807; goat; polyclonal & $1: 500$ \\
\hline \multicolumn{4}{|l|}{ Secondary antibodies } \\
\hline Biotinylated anti-rabbit IgG & $\begin{array}{l}\text { Gamma immunoglobulins heavy and } \\
\text { light chains; IgG }\end{array}$ & $\begin{array}{l}\text { Vector Laboratories; BA-1000; AB_2313606; } \\
\text { goat; polyclonal }\end{array}$ & $1: 200$ \\
\hline AF594-anti-rabbit & $\begin{array}{l}\text { Gamma Immunoglobulins heavy and } \\
\text { light chains; IgG }\end{array}$ & $\begin{array}{l}\text { Molecular Probes; A11037; AB_2534095; goat; } \\
\text { polyclonal }\end{array}$ & $1: 500$ \\
\hline AF488-anti-rabbit & $\begin{array}{l}\text { Gamma immunoglobulins heavy and } \\
\text { light chains; IgG }\end{array}$ & $\begin{array}{l}\text { Molecular Probes; A11034; AB_2576217; goat; } \\
\text { polyclonal }\end{array}$ & $1: 500$ \\
\hline AF488-anti-chicken & $\begin{array}{l}\text { Gamma immunoglobulins heavy and } \\
\text { light chains; IgY }\end{array}$ & $\begin{array}{l}\text { Molecular probes; A11039; AB_142924; goat; } \\
\text { polyclonal }\end{array}$ & $1: 500$ \\
\hline AF594-anti-goat & $\begin{array}{l}\text { Gamma immunoglobulins heavy and } \\
\text { light chains; IgG }\end{array}$ & $\begin{array}{l}\text { Molecular Probes; A11058; AB_142540; } \\
\text { donkey; polyclonal }\end{array}$ & $1: 500$ \\
\hline \multicolumn{4}{|l|}{ Lectin stain } \\
\hline GS-IB 4 & $\begin{array}{l}\text { The GS-IB }{ }_{4} \text { was isolated from the } \\
\text { seeds of the G. simplicifolia }\end{array}$ & Molecular Probes; I21413: AB_2313921 & $1: 500$ \\
\hline
\end{tabular}

AF594-anti-goat (A11058, RRID: AB_142540) is a secondary antibody raised in donkey against heavy and light chains of goat gamma immunoglobulins IgG and conjugated with the Alexa Fluor ${ }^{\circledR} 594$ fluorescent dye (4 fluorophore molecules per IgG molecule with ideal excitation at $594 \mathrm{~nm})$.

Additionally, isolectin GS-IB 4 (Molecular Probes, I21413, RRID: $\left.A B \_2313921\right)$ was isolated from the seeds of the $G$. simplicifolia legume conjugated with the Alexa Fluor ${ }^{\circledR} 594$ fluorescent dye (6 fluorophore molecules per IgG molecule with ideal excitation at $594 \mathrm{~nm}$ ). Subunit $A$ binds preferentially to $\mathrm{N}$-acetyl-D-galactosamine end groups while the $B$ subunit is selective for terminal $\alpha-D$-galactosyl residues. It was used at a final concentration of 1:500.

The antibody specificity was assured by performing a battery of control experiments consisting in: (a) incubation of the sections without secondary antibodies to check for unspecific background or autofluorescence from the tissue; (b) elimination of the primary antibodies to check for unspecific cross-reactivity of the antibodies with other immunoglobins in the tissue; (c) incubation with the peroxidase reveal system (ABC) only to assure the specificity of the DAB deposits; (d) immunostaining of positive control tissue sections (brain sections from C57BL/6n young mice and dorsal root ganglion sections from TRPM8EYFP mice).

\subsection{4 | Image acquisition}

Bright field and fluorescence images were collected using a Leica DM 6000B microscope, equipped with a Leica CTR 6000 fluorescence filter set and a Leica DFC310 FX camera (Leica Microsystems, Germany) and with a Laser Scanning Spectral Confocal Microscope Olympus Fluoview FV1200 (Olympus Corp, Tokyo, Japan).

\section{3 | Electrophysiological recording of cultured TG neurons}

Primary cultures of TG obtained from TRPM8 ${ }^{\mathrm{BAC}}$-EYFP mice ( $3 \mathrm{M}$ or 24M) were prepared following the procedure described elsewhere (Madrid et al., 2009). In brief, TG dissociated cells were plated on poly- 
L-lysine-coated glass coverslips and cultured in Eagle's minimal essential medium (MEM) with Earle's BSS and L-glutamine plus $10 \%$ heatinactivated fetal bovine serum, $1 \%$ vitamin solution and $100 \mu \mathrm{g} / \mathrm{mL}$ penicillin/streptomycin (all from Invitrogen). Cells were used after 12$36 \mathrm{hr}$ in culture.

Coverslips were transferred to a $0.15 \mathrm{~mL}$ recording chamber (Warner Instrument Corporation, Hamden, CT) on the stage of an inverted microscope (Nikon Diaphot-TMD, Nikon Instruments, Tokyo, Japan) and superfused (1.5-3 $\mathrm{mL} \cdot \mathrm{min}^{-1}$ ) at basal temperature (32$34^{\circ} \mathrm{C}$, maintained with a computer-controlled Peltier device, Embit, Modena, Italy) with physiological solution. Before each recording, lighttransmitted and fluorescent images of each neuron were taken (filter cube for GFP: 41017_Nikon; Watec camera), and the fluorescence intensity of each recorded neuron was expressed as percent of the maximum value of fluorescence measured in the whole population, in non-saturating conditions. Cell membrane potentials were recorded using the perforated patch clamp technique. Pipettes of borosilicate glass (Harvard Apparatus, UK, 2-4 M 2 ) were filled with a solution containing (in mM): $105 \mathrm{~K}$ gluconate, $50 \mathrm{KCl}, 2 \mathrm{CaCl}_{2}, 1 \mathrm{MgCl}_{2}, 10 \mathrm{HEPES}$, and $0.2 \mathrm{mg} / \mathrm{mL}$ nystatin (pH 7.3 adjusted with $\mathrm{NaOH}$; final $\mathrm{Na}^{+}$concentration $\approx 10 \mathrm{mM}$ ). Electrophysiological signals were recorded with an Axopatch 200B patch-clamp amplifier (Molecular Devices, CA). Stimulus delivery, data acquisition and analysis were performed using pClamp 9.2 software (Molecular Devices). Cooling ramps to $20-22^{\circ} \mathrm{C}$ (50 s duration) and extracellular L-menthol $(100 \mu \mathrm{M})$ were used to study the functional characteristics of TRPM8 ${ }^{+}$neurons.

\subsection{Extracellular recording of corneal nerve terminals}

C57BL/6 mice aged 3M or 24M were killed by cervical dislocation and their corneas used for electrophysiological recordings of cold nerve terminals.

Extracellular recordings of single corneal nerve terminals in vitro were performed as described in previous studies (González-González et al., 2017; Parra et al., 2010). The eye ball and the attached optic nerve were dissected and fixed with a suction tube to the bottom of a recording chamber and were continuously perfused with a solution ( $\sim 310 \mathrm{mOsm} \cdot \mathrm{L}^{-1}$ ) of the following composition (in $\mathrm{mM}$ ): $128 \mathrm{NaCl}, 5$ $\mathrm{KCl}, 1 \mathrm{NaH}_{2} \mathrm{PO}_{4}, 26 \mathrm{NaHCO}_{3}, 2.4 \mathrm{CaCl}_{2}, 1.3 \mathrm{MgCl}_{2}$, and $10 \mathrm{~d}$-glucose. The solution was bubbled with carbogen gas $\left(5 \% \mathrm{CO}_{2}\right.$ and $\left.95 \% \mathrm{O}_{2}\right)$ and maintained at the desired temperature with a Peltier device. A borosilicate glass microelectrode (tip diameter $\sim 50 \mu \mathrm{m}$ ) with an $\mathrm{Ag} / \mathrm{AgCl}$ wire inside and filled with the extracellular solution was placed in contact with the cornea surface using a micromanipulator. Gentle suction was then applied to record nerve terminal impulse (NTI) activity. NTIs were amplified with an AC amplifier (Neurolog NL104, Digitimer, Welwyn, UK) and digitized at $10 \mathrm{KHz}$ and stored in a computer using a CED micro 1401 interface and Spike 2 software (both from Cambridge Electronic Design, Cambridge, UK). Only recording sites where the NTI activity arose from a single nerve terminal were used for further analysis. At these sites, the NTIs were clearly distinguished from noise ( $\sim 10$ $\mu \mathrm{V}$ peak to peak) and identifiable by their similar waveform shape and firing pattern as arising from a single nerve terminal (Brock et al., 1998).
To minimize the effects introduced by the deterioration of the preparation with time, the total duration of the experiment was restricted to a maximum of $5 \mathrm{~h}$.

\subsection{1 | Experimental protocol}

The corneal surface was systematically explored with the microelectrode, from the center to the periphery, keeping the microelectrode in place at each location for $2 \mathrm{~min}$ to detect the possible occurrence during this time of at least one spontaneous NTI. The appearance of activity after application of the pipette onto the cornea was used to ascertain the successful location of a responsive sensory nerve terminal (González-González et al., 2017).

Cold thermoreceptor terminals were recognized either by the immediate detection of ongoing NTI activity at the control temperature of the bath $\left(\sim 34^{\circ} \mathrm{C}\right)$, which increased markedly in response to cooling, or by a NTI discharge in response to cooling, in terminals that had fired at least one NTI during the 2 min waiting period following application of the pipette to the cornea (González-González et al., 2017; see "Results" section). For cold stimulation, a cooling ramp was applied from the mean basal temperature of $34^{\circ} \mathrm{C}$ down to $12-13^{\circ} \mathrm{C}$ at a mean rate of $0.7 \pm 0.03^{\circ} \mathrm{C} \cdot \mathrm{s}^{-1}$. Temperature was returned to basal values at the end of cold thermal stimuli at a similar rate.

Mechanical stimulation was performed by gentle $(20 \mu \mathrm{m})$ forward displacement of the recording electrode against the ocular surface for $2 \mathrm{~s}$. Chemical stimulation with $L$-menthol $(20 \mu \mathrm{M})$ was carried out by shifting the perfusion from saline solution to saline solution plus the drug. A cooling ramp from $34^{\circ} \mathrm{C}$ was applied 2 min after the onset of perfusion with menthol, followed by a washing period of at least $5 \mathrm{~min}$ before testing other stimuli. Stimulation with a hyperosmolar solution was carried out by shifting the perfusion from the control solution to a $397 \mathrm{mOsm} . \mathrm{L}^{-1}$ solution for $2 \mathrm{~min}$ followed by a $5 \mathrm{~min}$ washing period.

\subsection{2 | Solutions}

L-Menthol (Sigma-Aldrich) was prepared as a $20 \mathrm{mM}$ stock solution in ethanol and diluted to a final concentration of $20 \mu \mathrm{M}$ with saline solution. Hyperosmolar solutions were prepared by adding $\mathrm{NaCl}(3 \mathrm{M})$ to the physiological saline solution $\left(310 \pm 1.5 \mathrm{mOsm} \cdot \mathrm{L}^{-1}\right)$ until reaching the desired osmolarity value of $397 \mathrm{mOsm} \cdot \mathrm{L}^{-1}$, measured with a freezing point osmometer (OSMOSTAT OM-6020, Kyoto Daiichi Kagaku, Kyoto, Japan).

\section{5 | Tear flow and tear osmolarity measurements}

Basal tear flow was measured in both eyes in $3 \mathrm{M}$ and $24 \mathrm{M}$ anesthetized TRPM8 $8^{\mathrm{BAC}}$-EYFP and C57BL/6 mice $(n=110)$ using phenol red threads (Zone-Quick, Menicon Pharma S.A., Graffenstaden, France) gently placed between the lower lid and the bulbar conjunctiva at the nasal angle during $1 \mathrm{~min}$ (Parra et al., 2010). No differences in the tear flow measurements were observed between TRPM8 ${ }^{\text {BAC }}$-EYFP and C57BL/6 mice. Therefore, data from both strains were analyzed together.

Osmolarity of the tear fluid was measured in C57BL/6 mice of different ages, using the TearLab Osmolarity System (OcuSense Inc., San 
Diego, CA). Tear fluid (50 nL) was collected from restrained, awake mice by gently placing the probe of the instrument into the meniscus formed at the nasal side of the inferior lid margin. Samples were obtained from both eyes in each mouse.

\section{6 | Data analysis}

\subsection{1 | Morphological data}

Whole-mounted corneas were divided into four quadrants. Epithelial innervation densities were determined in one central and two peripheral zones of each quadrant. The peripheral zones were defined as two $0.25 \mathrm{~mm}^{2}$ square regions (a $500 \times 500 \mu \mathrm{m}$ box) whose peripheral borders were $\sim 200 \mu \mathrm{m}$ away from the limbus internal border. The two peripheral zones were separated $500 \mu \mathrm{m}$ from each other. The central zone was defined as a $0.25 \mathrm{~mm}^{2}$ region, $500 \mu \mathrm{m}$ away from the peripheral boxes, that is, located at a distance of $1.2 \mathrm{~mm}$ from the limbus. Corneal nerve densities in the $0.25 \mathrm{~mm}^{2}$ boxes were determined from microphotographs captured with a Leica DM6000B light microscope. Two independent images were obtained from each $0.25 \mathrm{~mm}^{2}$ zone: one image was taken at the level of subbasal fibers, and the other at the level of the corneal epithelium layers, including the intraepithelial nerve terminals that derive from subbasal axons. Images were analyzed using the image analysis software FIJ (ImageJ 1.4, NIH, Bethesda, MD). Nerve density was calculated as the number of subbasal nerves or nerve terminals per $\mathrm{mm}^{2}$. Subbasal nerves were quantified as the number of them intersecting a line drawn inside the square area. The total number of the intraepithelial nerve terminals was counted inside each square area, defining the type of nerve terminal (simple, ramified, or complex) (Ivanusic et al., 2013). No differences in the number of subbasal nerves and nerve terminals per $\mathrm{mm}^{2}$ were observed between peripheral and central zones both in $3 \mathrm{M}$ and $24 \mathrm{M}$ mice. Therefore, values from both areas were averaged. Penetration sites of subepithelial bundles through the basal lamina were counted throughout the total area of the cornea and expressed as penetrations per $\mathrm{mm}^{2}$.

Counts of TG neurons were performed on reconstructions of the ganglion made by tiling each image of the serial TG sections under the fluorescence microscope using a $20 \times$ objective magnification, a motorized slide holder, and the Tile Scan module of the Leica AF6000 software, so that the entire extension of the ganglion was scanned and imaged. For the quantitation of the number of TRPM8 ${ }^{\text {BAC }}$-EYFP neurons in the TG, the FIJl software was used. Only neurons with a visible nucleus were counted. Neurons exhibiting a fluorescence intensity between cero and 90 arbitrary units on a 256-channel gray scale were considered weak fluorescent neurons. To avoid overestimation of the number of TG neurons, images of one in every nine microtome sections (that is, one image in every 63 microns) were analyzed. A minimum of three TG of each group were used.

\subsubsection{Analysis of NTI activity}

In computer-stored recordings of NTI activity of corneal nerve terminals, the following parameters were analyzed off-line:
- Background activity: Mean basal ongoing frequency in impulses per second (imp. $\mathrm{s}^{-1}$ ) at $34^{\circ} \mathrm{C}$, measured during the $30 \mathrm{~s}$ preceding the onset of a cooling ramp.

- Cooling threshold: Temperature $\left({ }^{\circ} \mathrm{C}\right)$ during a cooling ramp at which NTI frequency increased to a value that was the mean NTI frequency measured during the 10 -s period preceding the onset of a cooling ramp plus 3 times its standard deviation.

- Cooling response: The increase in firing rate (imp. $\mathrm{s}^{-1}$ ), measured between the cooling threshold and the peak frequency value reached during a cooling ramp.

\section{7 | Statistical analysis}

Data were analyzed using SigmaStat v3.5 (Systat Software, Point Richmond, CA). Statistical significance was determined by Mann-Whitney $U$ test or $Z$ test for morphological and tearing studies; $t$-test or oneway ANOVA followed by Bonferroni or Dunn's post hoc test for analysis of data of electrophysiological recording of cultured TG neurons; $t$ test or Mann-Whitney test for analysis of data of extracellular electrophysiological recordings. ${ }^{*} p<.05,{ }^{* *} p<.01,{ }^{* * *} p<.001$.

\section{3 | RESULTS}

\section{1 | TRPM8-EYFP ${ }^{+}$TG neurons exhibit different fluorescence levels}

Microscopic inspection of EYFP fluorescence in TG cell bodies and cor-

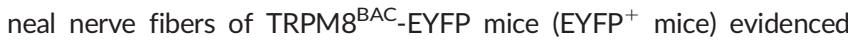
clear differences in fluorescence intensity both between individual somas and peripheral axons (Figure 1).

\subsection{1 | Cell body}

$17.8 \pm 0.9 \%$ of the neurons counted $(2268.4 \pm 266.5$ neurons per ganglion, $n=3$ ) in TG tissue sections of $3 \mathrm{M} \mathrm{EYFP}^{+}$mice displayed fluorescence (Figure 1a). In $56.3 \pm 1.3 \%$ of them, fluorescence intensity was high (>90 arbitrary units on a 256-channel gray scale) being thus called intensely fluorescent (IF) neurons. The majority of these neurons were peripherin positive and CGRP negative (Table 2). The remaining EYFP ${ }^{+}$ neurons $(43.7 \pm 1.3 \%)$ showed a weaker fluorescence intensity $(\leq 90$ arbitrary units on the 256-channel gray scale) and were named weakly fluorescent (WF) neurons (Figure 1a); almost half of them were immunoreactive to CGRP (Table 2). Both IF and WF neurons were IB4 negative (data not shown). Immunoreactivity to other neuronal markers (neurofilaments, TrkA) differed between IF and WF neurons (Table 2). In TG cultures, the two populations of IF and WF neurons were also clearly differentiated (see below).

\subsection{2 | Peripheral axons}

Corneal $\mathrm{EYFP}^{+}$axons were easily recognized within stromal nerve trunks and their extensively ramified, ascending intraepithelial branches, by their YFP immunofluorescence (Figure $1 \mathrm{~b}-\mathrm{e}$ ), and specific immunoperoxidase staining (Figure 2). 

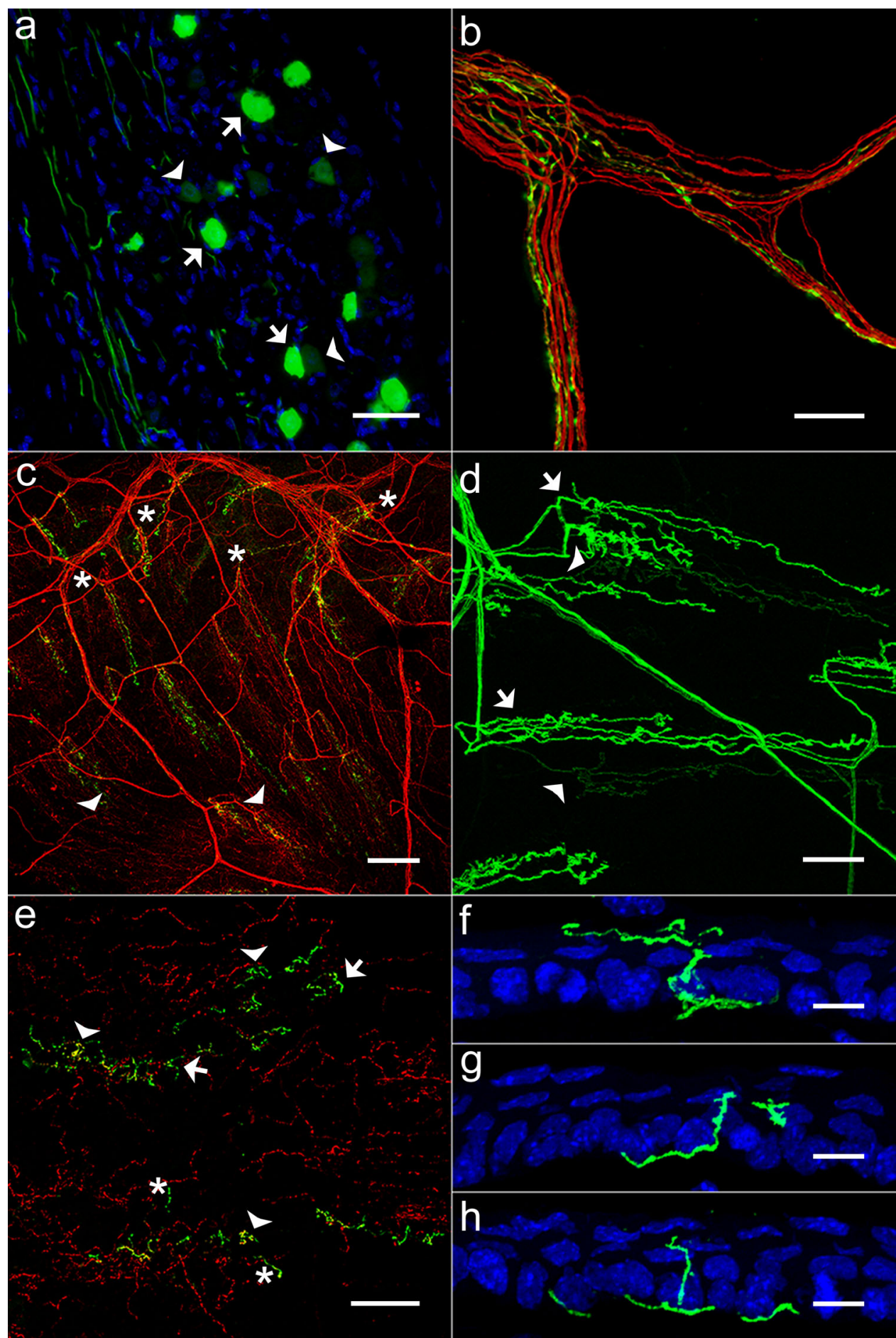

FIGURE 1 Immunostaining of TG neurons and peripheral corneal nerve branches of 3 M TRPM8 ${ }^{\text {BAC }}$-EYFP mice. (a) Fluorescence in IF (arrows) and WF (arrowheads) TG neurons. (b) Stromal nerve bundle containing EYFP ${ }^{+}$green axons mixed with non-EYFP ${ }^{+}$anti- $\beta$ III tubulin red axons. (c) Lowmagnification image showing penetrations through the basal lamina of ascending peripheral (asterisks) and central (arrowheads) nerve branches. (d) $\mathrm{EYFP}^{+}$nerve fibers displaying intense (arrows) and weak (arrowheads) fluorescense. (e) TRPM8 ${ }^{+}$intraepithelial, complex (arrowheads), ramifying (arrows), and simple (asterisk) terminal branches. ( $f-h)$ Corneal cross sections showing the ascending trajectory within the corneal epithelium layers of presumed complex (f), ramified (g) and simple (h) immunofluorescent terminal axons. Epithelium cell nuclei are counterstained with DAPI. Scale bars: $a$ and b, $50 \mu \mathrm{m} ; \mathrm{c}, 150 \mu \mathrm{m} ; \mathrm{d}$ and e, $75 \mu \mathrm{m} ; \mathrm{f}-\mathrm{h}, 10 \mu \mathrm{m}$

Corneal $\mathrm{EYFP}^{+}$axons of the subbasal plexus were morphologically heterogeneous. About half of them were IF, thick axons and showed beads along their length. The other half appeared as less intense fluorescent (WF), thinner, smooth axons (Figures $1 \mathrm{~d}$ and 2a). Overall mean density of subbasal EYFP ${ }^{+}$fibers was $22.4 \%$ of the total number of corneal sensory fibers running in 
TABLE 2 Molecular phenotype of TRPM8-EYFP+ TG neurons in young and aged mice

\begin{tabular}{|c|c|c|c|c|}
\hline & \multicolumn{2}{|c|}{ \% IF-EYFP-TRPM8 neurons } & \multicolumn{2}{|c|}{$\%$ WF-EYFP-TRPM8 neurons } \\
\hline & 3-month-old mice & 24-month-old mice & 3-month-old mice & 24-month-old mice \\
\hline Peripherin-IR & $\begin{array}{l}7.7 \pm 0.5 \\
(79.2 \pm 4.1)\end{array}$ & $\begin{array}{l}7.6 \pm 1.0 \\
(74.6 \pm 4.9)\end{array}$ & $\begin{array}{l}4.1 \pm 0.6 \\
(53.4 \pm 4.9)\end{array}$ & $\begin{array}{l}7.9 \pm 0.4^{* *} \\
(56.0 \pm 5.0)\end{array}$ \\
\hline NF200-IR & $\begin{array}{l}1.3 \pm 0.1 \\
(12.1 \pm 1.3)\end{array}$ & $\begin{array}{l}2.8 \pm 0.6^{* *} \\
(22.5 \pm 2.4)\end{array}$ & $\begin{array}{l}1.6 \pm 0.4 \\
(20.2 \pm 3.0)\end{array}$ & $\begin{array}{l}2.7 \pm 0.3 \\
(17.1 \pm 2.5)\end{array}$ \\
\hline TrkA-IR & $\begin{array}{l}1.3 \pm 0.3 \\
(13.8 \pm 2.4)\end{array}$ & $\begin{array}{l}1.6 \pm 0.5 \\
(16.4 \pm 3.8)\end{array}$ & $\begin{array}{l}3.9 \pm 0.7 \\
(48.7 \pm 5.7)\end{array}$ & $\begin{array}{l}5.2 \pm 0.6^{*} \\
(61.2 \pm 2.4)\end{array}$ \\
\hline CGRP-IR & $\begin{array}{l}0 \pm 0 \\
(0 \pm 0)\end{array}$ & $\begin{array}{l}0 \pm 0 \\
(0 \pm 0)\end{array}$ & $\begin{array}{l}3.6 \pm 1.2 \\
(44.1 \pm 11.4)\end{array}$ & $\begin{array}{l}4.2 \pm 0.4^{*} \\
(43.9 \pm 2.3)\end{array}$ \\
\hline
\end{tabular}

Note. Data of IF and WF neurons are expressed as percentage of total number of neurons counted in the TG and compared as a function of age using the $z$ test. ${ }^{*} p<.05 ;{ }^{* *} p<.01$. The data in parenthesis give the proportion of IF and WF TRPM8-EYFP ${ }^{+}$neurons, expressed as percentage of the total number of TRPM8-EYFP ${ }^{+}$TG neurons.

the leashes (Figure 1c). The ascending terminal branches from the leashes end superficially as intraepithelial endings (Figures $1 \mathrm{e}-\mathrm{h}$ and $2 \mathrm{~b}$ ). Mean density of intraepithelial endings of $3 \mathrm{M}$ mice was $527.8 \pm 23.2$ endings $/ \mathrm{mm}^{2}(n=3) ; 29.6 \%$ of this total were $\mathrm{EYFP}^{+}$endings of variable morphological complexity (Ivanusic et al., 2013). A majority $(51.1 \pm 2.1 \%)$ of the IF ascending branches formed "complex" endings; a smaller proportion (20.3 \pm $2.8 \%)$ produced "ramifying" nerve endings or terminate as "simple" nerve endings $(28.6 \pm 0.6 \%)$. In contrast, WF axons branched less in the subbasal plexus and formed simple $(57.9 \pm 0.9 \%)$ or ramifying $(31.7 \pm 1.8 \%)$ ending types; only $10.4 \pm 2.7 \%$ of them produced complex nerve endings.

\section{2 | Fluorescence intensity in TRPM8-EYFP ${ }^{+}$ neurons correlates with their cold sensitivity}

\subsection{1 | Cell body}

To evaluate the possible correlation between fluorescent intensity in EYFP $^{+}$TG neurons and their TRPM8 expression levels, we analyzed the relationship between somatic fluorescence intensity and electrophysiological responses to cold and menthol in TG cultured neurons of $3 \mathrm{M}$ mice. We recorded changes in membrane potential $\left(E_{m}\right)$ to cooling ramps and during application of menthol $(100 \mu \mathrm{M})$ in the two groups of $\mathrm{EYFP}^{+}$neurons (Figure 3a,b): IF neurons (mean fluorescence $=64.3 \pm$ $5.6 \%$ of maximum), WF neurons (mean fluorescence $=6.3 \pm 1.0 \%$ of maximum), and in NonF neurons (no fluorescence).
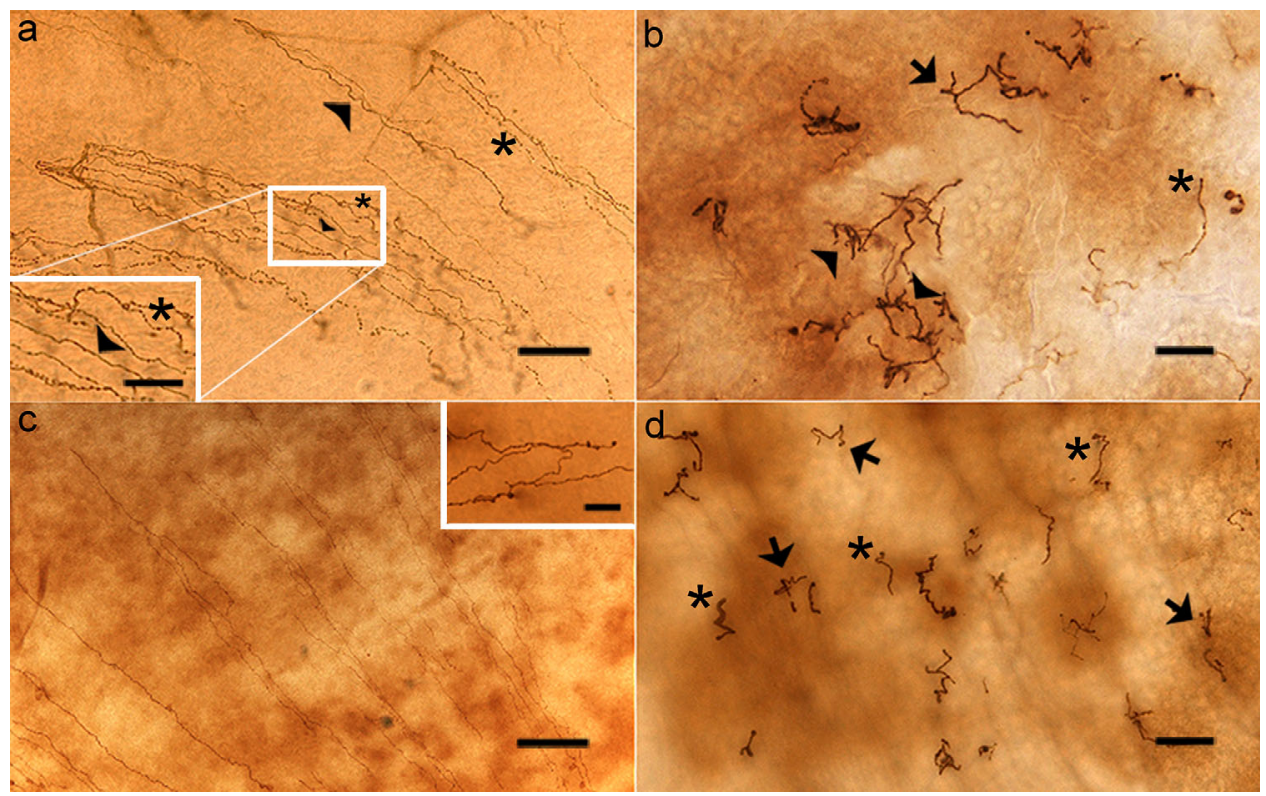

FIGURE 2 Anti-GFP immunostaining of corneal nerve fibers in the periphery of whole-mounted corneas of $3 \mathrm{M}$ and $24 \mathrm{M}$ old mice. (a and b) $3 \mathrm{M}$ mouse. (a) Subbasal EYFP ${ }^{+}$longer, beaded (asterisks) and smooth, shorter (arrowheads) axons. Inset: Higher magnification the dashed area. (b) Intraepithelial, terminal branches forming complex (arrowhead), ramifying (arrows) and simple (asterisks) endings. (c and d) $24 \mathrm{M}$ mouse. (c) EYFP ${ }^{+}$subbasal axons, some ending abruptly forming "collapsed axons" (inset). (d) Intraepithelial terminal branches generally form ramifying (arrows) or simple endings (asterisks). Scale bars: a, $100 \mu \mathrm{m}$, inset, $50 \mu \mathrm{m}$; b and d, $20 \mu \mathrm{m}$; c, $100 \mu \mathrm{m}$, inset $20 \mu \mathrm{m}$ 
a

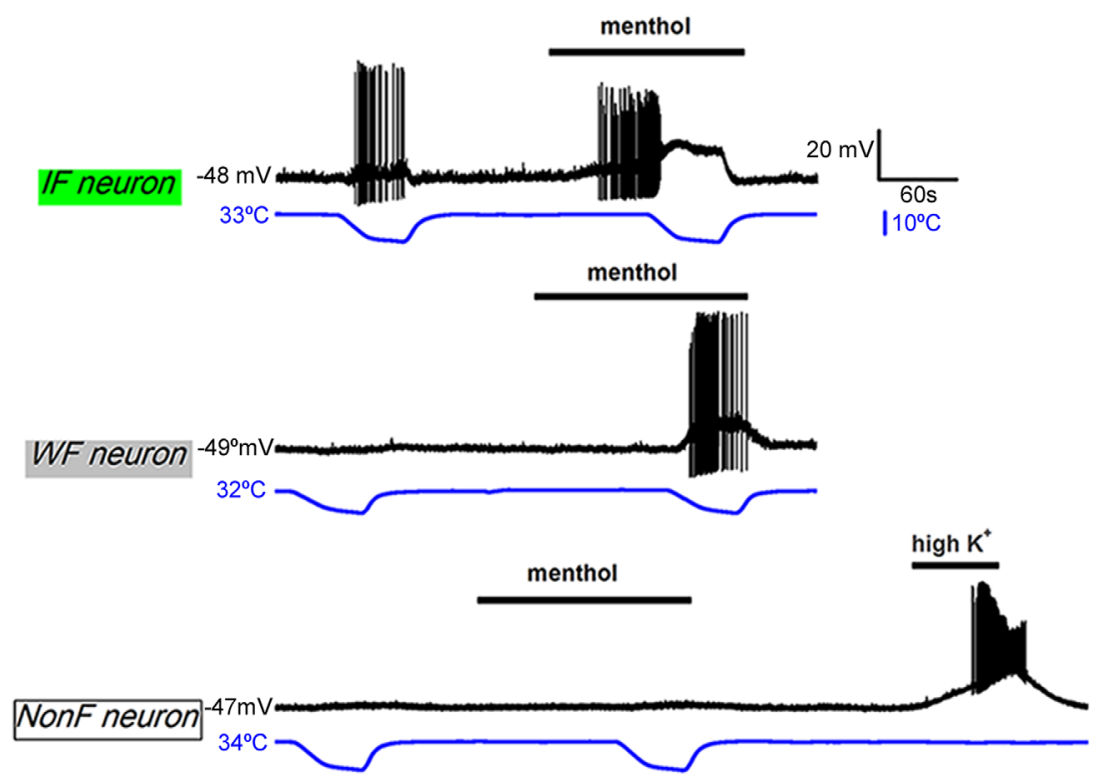

b
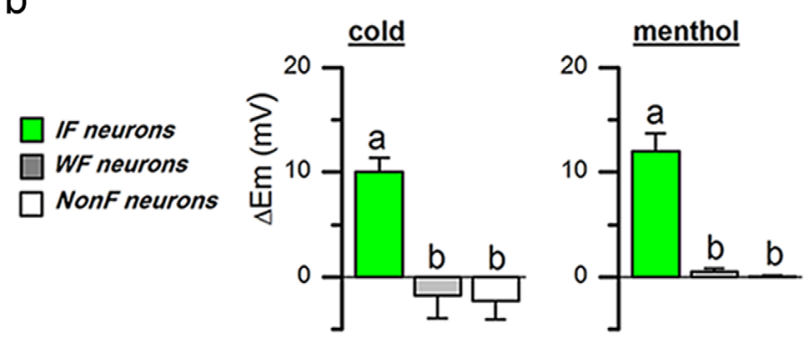

C IF neurons $\square$ WF neurons
O young mice

- aged mice
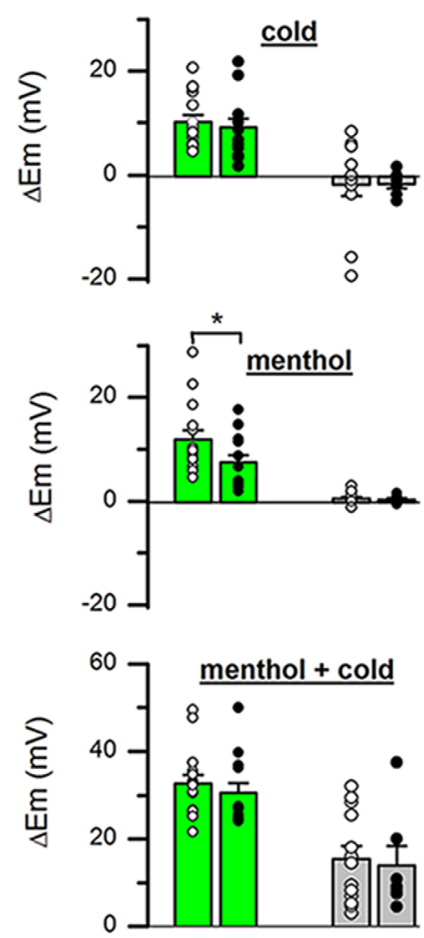

FIGURE 3 Correlation between fluorescence intensity of cultured TRPM8-EYFP ${ }^{+}$TG neurons and cold and menthol sensitivity. (a) Sample recordings obtained from typical TG neurons of $3 \mathrm{M}$ mice presenting IF, WF and NonF neurons. Membrane potential $\left(E_{m}\right)$ trace is represented in black and bath temperature in blue. Horizontal black bars mark perfusion with $100 \mu \mathrm{M}$ menthol and $37.5 \mathrm{mM} \mathrm{K}^{+}$, respectively. (b) Average changes in $E_{m}$ elicited by a cold ramp, menthol, and menthol plus a cold ramp in the three classes of neurons. Data are mean \pm SEM of IF $(n=15)$, WF $(n=13)$ and NonF $(n=12)$ neurons. One-way ANOVA $(p<.001$ in all cases) with Bonferroni or Dunn's post hoc test ( $p<.001$ for cold stimulus; $p<.05$ for menthol and menthol + cold stimuli). (c) Average (bars) and individual (circles) changes in $E_{m}$ elicited by cold ramps, menthol and menthol plus cold in IF and WF neurons from 3M (O), and $24 \mathrm{M}(\bullet)$ mice. ${ }^{*} p=.05$ by $t$ test

IF neurons were depolarized by cold and menthol $\left(\Delta E_{m}=10.0 \pm\right.$ $1.4 \mathrm{mV}$ and $12.0 \pm 1.7 \mathrm{mV}$, respectively, $n=15$ ). In addition, their responses to cooling were strongly potentiated by menthol $\left(\Delta E_{m}=32.7 \pm 2.0 \mathrm{mV}\right)$. In WF neurons $(n=13)$, the effects of cold or menthol on $E_{m}$, when applied separately, were weak or negligible, although all neurons were depolarized by simultaneous application of both stimuli, leading to action potential firing in a few of them (4/13, Figure 3a). Finally, none of the NonF neurons $(n=12)$ showed $E_{m}$ changes during application of cold or menthol; their functional integrity was proved by the strong depolarization evoked by high $\mathrm{K}^{+}$exposure $\left(\Delta E_{m}=25.7 \pm 1.9 \mathrm{mV} ; n=12\right)$. There were no significant differences between the three classes of neurons recorded regarding values of resting $E_{m} \quad(\mathrm{IF}=-57.3 \pm 2.2 \mathrm{mV} ; \quad \mathrm{WF}=-56.0 \pm 2.7 \mathrm{mV}$; Non$\mathrm{F}=-53.6 \pm 2.5 \mathrm{mV} ; p=.571$, one-way ANOVA), or membrane capacitance $(\mathrm{IF}=11.8 \pm 1.3 \mathrm{pF} ; \mathrm{WF}=14.4 \pm 1.7 \mathrm{pF} ; \mathrm{NonF}=14.7 \pm 1.5 \mathrm{pF}$; $p=.340$, one-way ANOVA). In sharp contrast with the typical ongoing firing of most peripheral corneal cold nerve terminals, only one of the
IF cold-sensitive neurons exhibited spontaneous discharge at $33^{\circ} \mathrm{C}$ Altogether, these results indicate (Figure $3 b$ ) that IF neurons are more sensitive to TRPM8 agonists (cold and menthol) than WF neurons, suggesting their differential TRPM8 expression levels. Figure $3 c$ presents the electrophysiological parameters of fluorescent neurons in young mice, to allow their comparison with those of old animals, as discussed below.

\subsection{2 | Peripheral terminals}

The presence of two-functional subpopulations of cold thermoreceptors with different sensitivity to cooling (González-González et al., 2017) was confirmed in 18 corneas of 3M C57BL/6 mice. In 5.7

$1.6 \%$ of all recording attempts, terminals exhibiting a robust ongoing repetitive activity (more than $2 \mathrm{imp} \cdot \mathrm{s}^{-1}$ ) at the holding temperature of $34^{\circ} \mathrm{C}$ were identified. These endings also gave a vigorous response to cooling ramps, firing readily during temperature decreases (Figure 4a). Menthol $(20 \mu \mathrm{M})$ and hyperosmolar solutions (397 $\left.\mathrm{mOsm} \cdot \mathrm{L}^{-1}\right)$ 
a

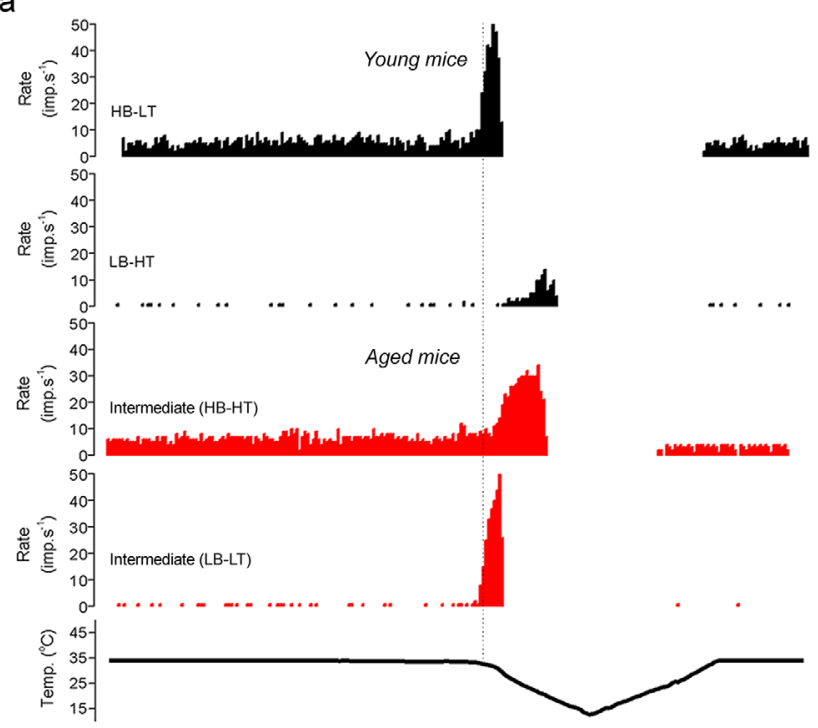

b

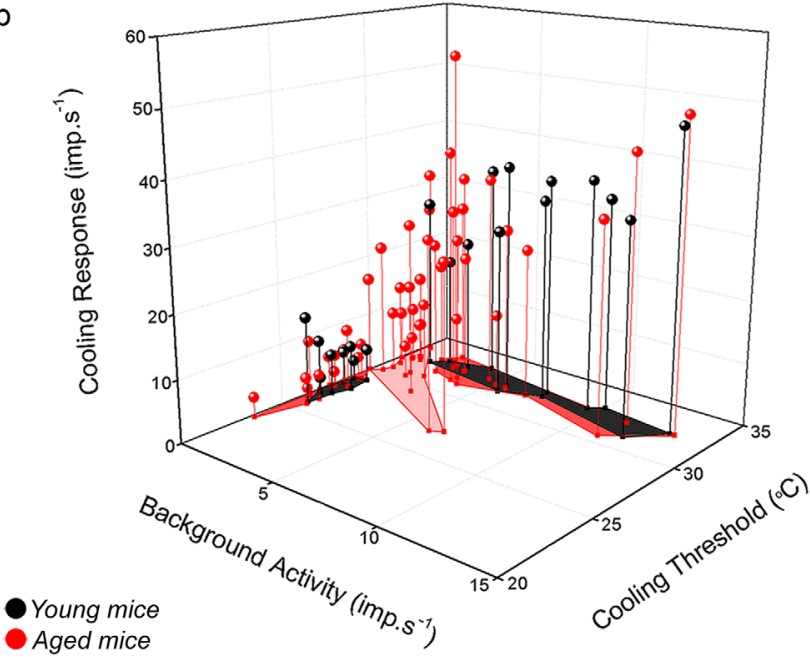

FIGURE 4 Aging effects on NTI activity of corneal cold-sensitive terminals. (a) Examples of the NTI discharge and the response to a cooling ramp from 34 to $15^{\circ} \mathrm{C}$ (lowest trace) recorded in the different classes of cold-sensitive terminals. Traces of high background, low threshold (HB-LT) and low background, high threshold (LB-HT) NTI activity were obtained from $3 \mathrm{M}$ mice. Those from terminals exhibiting intermediate properties (high background, high threshold, HB-HT and low background, low threshold, LB-LT; in red) were obtained from 24M mice. (b) Plot of individual cold-sensitive endings attending to background activity at $34^{\circ} \mathrm{C}$, firing response to cooling and cooling threshold in ${ }^{\circ} \mathrm{C}$. Data from $3 \mathrm{M}$ mice (black) and from $24 \mathrm{M}$ mice (red) are projected onto the horizontal plane as black or red-filled areas, separating the intermediate fibers of the last group (light red) to highlight their differences with HB-LT and LB-HT terminals

increased significantly their spontaneous activity and peak firing response to cooling ramps. Accordingly, these endings were classified as high-background, low-threshold (HB-LT) cold thermoreceptors.

In $2.6 \pm 1.2 \%$ of the recording attempts, low-background, highthreshold (LB-HT) cold thermoreceptor terminals were also identified. These endings exhibited a very low mean firing frequency at $34^{\circ} \mathrm{C}$ and responded to cooling ramps with a relatively modest increase in firing frequency, starting at a mean threshold temperature $4-5^{\circ} \mathrm{C}$ below the value seen in HB-LT cold receptor terminals (Figure 4a). Menthol (20 $\mu \mathrm{M})$ and perfusion with $397 \mathrm{mOsm} \cdot \mathrm{L}^{-1}$ solution augmented their spontaneous activity and reduced their threshold, also increasing the maximum firing response to cooling ramps. Table 4 summarizes the firing characteristics of HB-LT and LB-HT cold thermoreceptor endings in young mice.

\subsection{The number and molecular phenotype of TRPM8-EYFP ${ }^{+}$TG neurons and the architecture and density of corneal axonal branches change with age}

\subsection{1 | Cell body}

In aged, $24 \mathrm{M}$ mice, $21.6 \pm 1.1 \%$ of the TG neurons $(2723.0 \pm 263.8$ neurons per ganglion, $n=3$ ) were $\mathrm{EYFP}^{+}$, a proportion significantly larger than in young animals ( $p=.002, z$ test). This increase was accompanied by a higher percentage of WF neurons $(10.7 \pm 0.9 \%$ in $24 \mathrm{M}$ mice vs. $7.8 \pm 0.4$ in $3 \mathrm{M}$ mice, $p<.001, z$ test). The proportion of WF neurons expressing peripherin, TrkA, and CGRP also increased significantly with age (Table 2).

\subsection{2 | Peripheral axons}

In $24 \mathrm{M}$ mice, the number and architecture of corneal sensory nerves including the subpopulation of EYFP ${ }^{+}$fibers appeared strikingly modified in comparison with younger animals (Figure 2 and Table 3 ). In this age group, the density of penetration points into the lamina basal containing EYFP axons was significantly higher than in young animals (49.6\% increase, $p=.019$, Table 3 ). This was due to a higher number of penetration points at the periphery in old mice $(15.3 \pm 1.5$ penetrations $/ \mathrm{mm}^{2}$ vs. $8.6 \pm 0.6$ penetrations $/ \mathrm{mm}^{2}$, in $24 \mathrm{M}$ and $3 \mathrm{M}$ mice, respectively, $p=.004$ ), while in the center of the cornea differences in penetration points density with age were not significant.

Notably, in $24 \mathrm{M}$ mice, nearly all $(95.1 \pm 2.9 \%)$ TRPM8-EYFP $^{+}$ axons were nonbeaded (smooth), faintly fluorescent, and remarkably long and thin (compare Figure 2a,c), often reaching the center of the cornea, in sharp contrast with young animals (average length of the subbasal axons: $304.9 \pm 14.0 \mu \mathrm{m}$ vs. $227.6 \pm 11.6 \mu \mathrm{m}, p=.002, t$ test). On the other hand, the density of EYFP ${ }^{+}$subbasal axons of $24 \mathrm{M}$ mice was significantly lower $(27.7 \%)$ than in $3 \mathrm{M}$ mice $(p<.001$; Table 3$)$. Also, they were distributed differently within the leashes, with more leashes containing $\mathrm{EYFP}^{+}$axons in aged mice albeit with a lower mean number of fluorescent axons per leash.

The total density of $\mathrm{EYFP}^{+}$terminals in $24 \mathrm{M}$ mice was $35.6 \%$ lower than in $3 \mathrm{M}$ mice $(p<.001)$. In addition, the proportion of the different morphological subtypes of $\mathrm{EYFP}^{+}$intraepithelial nerve endings was markedly altered for complex endings in aged mice; there, $59.7 \pm$ $0.7 \%$ of terminals had simple endings (3M: $43.4 \pm 1.7, p=$ n.s., MannWhitney $U$ test), $25.6 \pm 1.2 \%$ had ramifying endings (3M: $26.0 \pm 1.7 \%$, $p=$ n.s., $z$ test), and only $2.6 \pm 0.7 \%$ had complex endings (3M: $30.6 \pm$ $1.7, p<.001, z$ test) (compare Figure $2 b, d)$. Moreover, $12.1 \pm 2.6 \%$ of the subbasal EYFP ${ }^{+}$axons ended abruptly within the subbasal plane without emitting any branches that ascend to terminate more 
TABLE 3 Morphological characteristics of TRPM8-EYFP ${ }^{+}$axons and epithelial nerve endings innervating the cornea of mice at different ages

\begin{tabular}{|c|c|c|}
\hline Morphometric parameter & 3-month-old mice & 24-month-old mice \\
\hline Penetration of subepithelial bundles (number $/ \mathrm{mm}^{2}$ ) & $\begin{array}{l}11.5 \pm 0.5 \\
n=5\end{array}$ & $\begin{array}{l}17.2 \pm 1.2^{* * *} \\
n=5\end{array}$ \\
\hline$\%$ beaded subbasal nerve axons & $\begin{array}{l}50.1 \pm 6.5 \\
n=3\end{array}$ & $\begin{array}{l}4.9 \pm 2.9^{* * *} \\
n=4\end{array}$ \\
\hline \% smooth subbasal nerve axons & $\begin{array}{l}49.9 \pm 6.5 \\
n=3\end{array}$ & $\begin{array}{l}95.1 \pm 2.9^{* * *} \\
n=4\end{array}$ \\
\hline Density of subbasal axons (number $/ \mathrm{mm}^{2}$ ) & $\begin{array}{l}126.4 \pm 5.9 \\
n=7\end{array}$ & $\begin{array}{l}91.6 \pm 4.2^{* * *} \\
n=10\end{array}$ \\
\hline Number of axons per leash & $\begin{array}{l}5.2 \pm 0.3 \\
n=3\end{array}$ & $\begin{array}{l}2.6 \pm 0.2^{* * *} \\
n=4\end{array}$ \\
\hline Density of terminal branches (number $/ \mathrm{mm}^{2}$ ) & $\begin{array}{l}156.2 \pm 8.0 \\
n=7\end{array}$ & $\begin{array}{l}111.2 \pm 5.6^{* * *} \\
n=10\end{array}$ \\
\hline
\end{tabular}

Note. Comparisons of measures performed in 24-month-old mice were made against the values obtained in 3-month-old mice. Mann-Whitney $U$ test was used except for the data of percentage of beaded and smooth subbasal axons, which were analyzed using a $z$ test. ${ }^{* * *} p<.001, n=$ number of mice.

superficially in the epithelium. We called such terminations, "collapsed axons" (see Figure 2c, inset) and were not found in young animals $(p=.009, z$ test $)$.

\section{4 | Aging modifies the electrophysiological responses of peripheral cold-sensitive endings but not of TG TRPM8-EYFP ${ }^{+}$neurons}

Next, we analyzed the functional changes developed with aging by TG $\mathrm{EYFP}^{+}$neurons and their cold-sensitive nerve terminals.

\subsection{1 | Cell body}

Cultured TG $\mathrm{EYFP}^{+}$neurons of $24 \mathrm{M}$ mice were also divided into IF and WF neurons. Even though they were not counted, WF neurons were clearly more abundant in these cultures compared with those from young animals. As in young mice, IF neurons were more sensitive to TRPM8 agonists than WF neurons (Figure 3c). $\Delta E_{m}$ observed in IF versus WF neurons during exposure to cold, menthol, and menthol plus cold were $9.1 \pm 1.6$ versus $-1.7 \pm 0.8 \mathrm{mV} ; 7.5 \pm 1.4$ versus $0.3 \pm$ $0.3 \mathrm{mV}$; and $30.6 \pm 2.1$ versus $14.0 \pm 4.3 \mathrm{mV}$, respectively. Moreover, the amplitudes of membrane depolarizations induced by cold exposure alone or in the presence of menthol were similar to those of young mice (see Figure 3c) for both neuronal types, IF and WF. Only in the group of the IF neurons of aged mice, the amplitude of the mentholevoked depolarization was slightly lower than in IF neurons of young animals ( $\Delta E_{m}=7.5 \pm 1.4 \mathrm{mV}$ vs. $12.0 \pm 1.7 \mathrm{mV} ; p=.05, t$ test). Resting membrane potential at $33^{\circ} \mathrm{C}$, membrane capacitance and fluorescence intensity of the recorded IF and WF neurons in aged animals did not differ from those reported in the same neuronal types of young mice. $\left(E_{m}=-53.7 \pm 2.7\right.$ and $-56.7 \pm 2.3 \mathrm{mV} ; C_{m}=12.7 \pm 1.4$ and $17.9 \pm$ $3.1 \mathrm{pF}$, and mean fluorescence $=60.3 \pm 5.1 \%$ and $8.8 \pm 2.5 \%$ for IF and WF neurons, respectively).

\subsection{2 | Peripheral terminals}

In 24M mice corneas, terminals displaying an ongoing activity $>2$ imp. $\mathrm{s}^{-1}$ at $34^{\circ} \mathrm{C}$, characteristic of HB-LT cold terminals of young

TABLE 4 Functional characteristics of corneal cold-sensitive nerve endings

\begin{tabular}{|c|c|c|c|c|c|}
\hline \multicolumn{2}{|l|}{ Cold terminal type } & \multirow{2}{*}{$\begin{array}{l}\left.\text { Background activity (imp } \cdot \mathrm{s}^{-1}\right) \\
6.8 \pm 1.1 \\
(n=12)\end{array}$} & \multirow{2}{*}{$\begin{array}{l}\text { Cooling threshold }\left({ }^{\circ} \mathrm{C}\right) \\
32.5 \pm 0.2 \\
(n=12)\end{array}$} & \multirow{2}{*}{$\begin{array}{l}\text { Cooling response }\left(\text { imp } \cdot \mathbf{s}^{-1}\right) \\
33 \pm 2.2 \\
(n=12)\end{array}$} & \multirow{2}{*}{$\begin{array}{l}\text { Successrate (\%) } \\
5.7\end{array}$} \\
\hline 3-month-old mice & HB-LT & & & & \\
\hline & LB-HT & $\begin{array}{l}0.5 \pm 0.1 \\
(n=8)\end{array}$ & $\begin{array}{l}28.1 \pm 0.5 \\
(n=8)\end{array}$ & $\begin{array}{l}6.6 \pm 1.3 \\
(n=8)\end{array}$ & 2.6 \\
\hline \multirow[t]{4}{*}{ 24-month-old mice } & HB-LT & $\begin{array}{l}4.7 \pm 0.8 \\
(n=20)\end{array}$ & $\begin{array}{l}32 \pm 0.2 \\
(n=20)\end{array}$ & $\begin{array}{l}24.6 \pm 2.3 \\
(n=20)\end{array}$ & 4.6 \\
\hline & $H B-H T$ & $\begin{array}{l}5.3 \pm 1.2 \\
(n=3)\end{array}$ & $\begin{array}{l}27.7 \pm 0.8 \\
(n=3)\end{array}$ & $\begin{array}{l}28.2 \pm 1.0 \\
(n=3)\end{array}$ & 0.6 \\
\hline & LB-HT & $\begin{array}{l}0.6 \pm 0.1 \\
(n=17)\end{array}$ & $\begin{array}{l}27.1 \pm 0.5 \\
(n=17)\end{array}$ & $\begin{array}{l}6.3 \pm 1.2 \\
(n=17)\end{array}$ & 4.0 \\
\hline & $L B-L T$ & $\begin{array}{l}0.5 \pm 0.1 \\
(n=11)\end{array}$ & $\begin{array}{l}32.1 \pm 0.3 \\
(n=11)\end{array}$ & $\begin{array}{l}13 \pm 2.6 \\
(n=11)\end{array}$ & 1.8 \\
\hline
\end{tabular}

Note. Success rate percentage indicates the percentage of successful attempts of recording a terminal from each group referred to the total number of attempts. HB, high-background activity; HT, high threshold; LB, low-background activity; LT, low-threshold; $n=$ number of endings. 


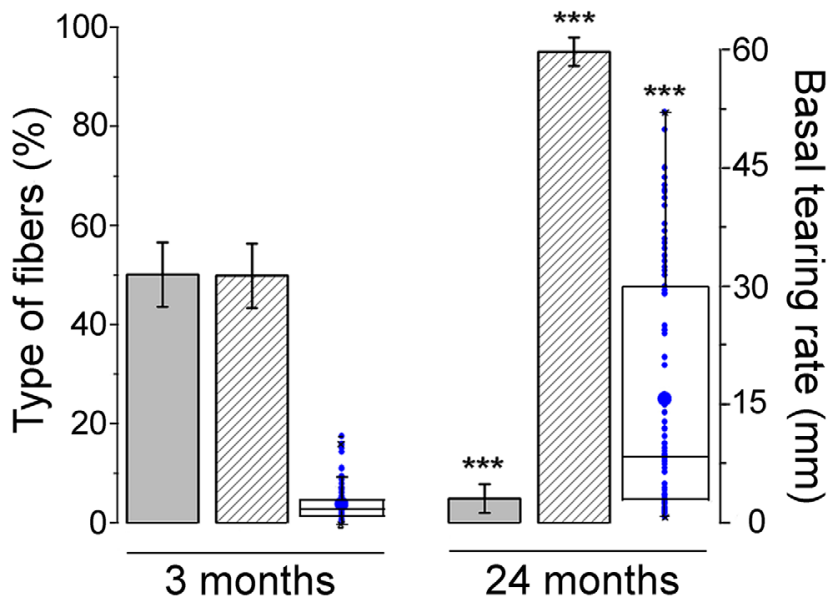

FIGURE 5 Change of basal tearing rate and TRPM8-EYFP ${ }^{+}$ subbasal nerve fiber density with aging. Bars represent the percentage of IF fibers (gray) and WF (stripped) in 3M and 24M mice $\left({ }^{* * *} p<.001, t\right.$ test). In the same age groups, individual values of basal tearing measured in $\mathrm{mm}$ of wet phenol red thread (small blue dots) and their mean value (large blue dot), median (horizontal line), 25th and 75th percentiles (white box limits), and 1st and 99th percentiles $(X)$ are also represented $\left({ }^{* * *} p<.001\right.$, Mann-Whitney $U$ test)

animals were found in $5.1 \pm 1.1 \%$ of the total recording attempts. As shown in Table 4, most of these terminals had a cooling threshold similar to HB-LT terminals of young animals, although they showed on the average lower mean values of background NTI frequency and weaker firing responses to cooling pulses. They also responded to $20 \mu \mathrm{M}$ menthol and to $397 \mathrm{mOsm} \cdot \mathrm{L}^{-1}$ solutions with a rise in background frequency and an enhancement of the maximum NTI firing response to cooling ramps. In aged mice, we also frequently encountered (5.8\% of recording sites) corneal cold terminals with very lowbackground activity and a weak response to cold that resembled the LB-HT units found in young animals (Table 4). Noteworthy, in 24M mice, we detected a small fraction of the spontaneously firing coldsensitive terminals had distinctly higher thresholds for activation during cooling (HB-HT terminals in Figure 4 and Table 4). Moreover, in $24 \mathrm{M}$ mice, a large proportion of the terminals with very low-basal activity at $34^{\circ} \mathrm{C}$ exhibited a remarkable sensitivity to cold, showing cold threshold values within the range observed in the canonical HB-LT cold thermoreceptor endings, although their impulse response to cooling ramps was significantly weaker (LB-LT cold terminals of Figure 4 and Table 4). Another notable observation made in aged mice was that the probability of detecting cold-sensitive terminals either with high or low background activity at $34^{\circ} \mathrm{C}$ was overall higher in comparison with young mice (Table 4).

In Figure 4b, we plotted all units recorded in young and old mice according to the values of the three parameters used for their functional characterization. This representation highlights the appearance in old mice of new, functionally distinct endings (drawn in light red in the horizontal plane) exhibiting a mixture of the firing characteristics of the two classes of cold-sensitive fibers typical of younger animals.

\section{5 | Aging alters tear's basal flow and osmolarity}

Mean basal tearing flow in anesthetized $3 \mathrm{M}$ TRPM8 ${ }^{\mathrm{BAC}}$-EYFP and C57BL/6 mice was $2.4 \pm 0.2 \mathrm{~mm}(n=66)$. In $24 \mathrm{M}$ mice, tearing rate values were more variable and significantly higher than in young animals (15.7 $\pm 1.6 \mathrm{~mm}, n=44 ; p<.001, t$ test) (Figure 5 ). Notably, the values of basal tearing flow augmented in parallel with the higher proportion of WF fibers, suggesting that basal tearing rate increased in parallel with the increase of WF and the decrease of IF corneal nerve fibers observed with aging (Figure 5). Finally, we measured mean tear osmolarity in $24 \mathrm{M}$, awake mice obtaining a mean value of $354.0 \pm 2.8$ $\left.\mathrm{mOsm} \cdot \mathrm{L}^{-1}, n=22\right)$. This value was significantly higher than in young adult awake mice $\left(346.3 \pm 2.4 \mathrm{mOsm} \cdot \mathrm{L}^{-1}, n=19, p=.008\right.$, MannWhitney $U$ test).

\section{4 | DISCUSSION}

We quantified EYFP-labeled, TRPM8-expressing TG neurons and axons in the mouse cornea, in combination with electrophysiological recordings and measures of tearing to follow their alterations with age. To our knowledge, this is the first description of aging related alterations in the morphology and function of cold thermoreceptor endings of any species.

\subsection{Cold-sensitive neurons and corneal nerve endings are morphologically and functionally heterogeneous}

TRPM8 channels are the main molecular transducers for cold temperature sensing in mammalian thermoreceptors (Knowlton et al., 2013; McKemy et al., 2002; Peier et al., 2002). Previous studies reported marked differences in menthol sensitivity and cold threshold of individual TG and DRG neurons (Babes et al., 2004; Viana et al., 2002), which were directly associated to the amplitude of their cold-evoked TRPM8 currents (Madrid et al., 2009).

Here, we found that somatic fluorescence intensity in TRPM8EYFP TG neurons of young adult mice correlated with the amplitude of cold- and menthol-evoked depolarizations, strongly suggesting that TRPM8 channel density is one determinant of cold sensitivity (de la Peña et al., 2005; Madrid et al., 2009; Morenilla-Palao et al., 2014; Xing et al., 2006). Other factors influencing cold sensitivity, including the variable expression of different potassium channels, were not explored in the present study (Madrid et al., 2006, 2009; MorenillaPalao et al., 2014; Viana et al., 2002). We also found differences in EYFP fluorescence intensity and cold sensitivity among TRPM8 ${ }^{+}$ peripheral sensory axons of the cornea, suggesting that their functional differences are linked to TRPM8 expression as well. Small and medium-size, nonpeptidergic IF-EYFP TG neurons are the likely origin of the strongly fluorescent, beaded axons which terminate in the corneal epithelium predominantly as CGRP-negative, complex nerve endings (Alamri et al., 2015; Ivanusic et al., 2013). The remarkable highthermal sensitivity to cold of IF-EYFP neurons are expected considering their high density of TRPM8 channels and low-Kv1 expression (Madrid 
et al., 2009). Furthermore, TRPM8 likely contributes to the ongoing activity of corneal cold thermoreceptors (Parra et al., 2010). Together, these findings suggest a high expression of TRPM8 in the strongly fluorescent, beaded axons; their predominately complex endings are possibly a biophysical reason for their characteristic spontaneous firing, low threshold and vigorous response to cooling typical of HB-LT cold thermoreceptors (Carr et al., 2009; González-González et al., 2017; Madrid et al., 2009; Olivares et al., 2015; Parra et al., 2010; Teichert et al., 2012).

WF neurons represent a second population of TRPM8-expressing TG neurons and are presumably the origin of corneal TRPM8-EYFP axons characterized by fainter fluorescence, smooth surface and thin diameter, terminating as simple or ramifying endings. In all likelihood, they correspond to the LB-HT corneal cold thermoreceptors (González-González et al., 2017). WF-TRPM8 ${ }^{+}$neurons are TrkA and CGRP positive, a phenotype observed in peptidergic polymodal nociceptors of other tissues (Abe et al., 2005; Knowlton et al., 2013; Takashima et al., 2007). It is worth noting that genetic deletion of TRPM8 channels or conditioned ablation of TRPM8-expressing neurons reduces markedly behavioral responses to innocuous but also to noxious cold, supporting the view that a part of the peripheral neurons expressing TRPM8 are connected to pain-labeled lines (Palkar et al., 2015). According to this interpretation, $\mathrm{TRPM}^{+}{ }^{+} \mathrm{TG}$ neurons are the origin of labeled sensory lines both for sensing innocuous ocular surface cooling chiefly involved in basal tearing regulation (HB-LT cold thermoreceptors) and for sensing of potentially injuring dryness, evoking discomfort, reflex tearing and blink responses (LB-HT cold thermoreceptors) (Belmonte et al., 2015, 2017; Kovács et al., 2016; Parra et al., 2010; Quallo et al., 2015).

\subsection{Morphological and functional changes in TRPM8-expressing neurons and corneal endings with age}

In spite of the quantitative differences in human life span, survival curves in mice resemble notably those seen in humans (Comfort, 1964). Indeed, mice have been used extensively to study the biological effects of aging (Wang \& Albers, 2009). This justifies the use of TRPM8 ${ }^{\mathrm{BAC}}$-EYFP transgenic mice to analyze the morphological and functional changes in the ocular surface innervation produced by aging.

Earlier morphological studies on age-induced variations in corneal innervation yielded conflicting results. In humans, nerve density measured in vivo (Parissi et al., 2013) or in stained corneas (He et al., 2010) decreases with age. Notably, in rats, density of subbasal corneal nerve fibers apparently rises with aging but is accompanied by a simultaneous, progressive decline of epithelial nerve endings (Dvorscak \& Marfurt, 2008). In mice, where subbasal corneal nerve density varies hugely among different strains, an overall reduction was reported in old animals (Reichard et al., 2016).

In our study, the number of TG neurons in old mice was not significantly different from younger animals suggesting that aging has a more pronounced effect on the architecture and density of peripheral sensory nerve terminal axons than on cell bodies. Nonetheless, the percentage of TRPM8 ${ }^{+}$neurons was larger, an increment that occurred mainly in the subpopulation of WF-EYFP TG neurons expressing peripherin, TrkA, and CGRP, a polymodal nociceptor immunoreactive phenotype, whereas the population of canonical low-threshold cold thermoreceptor neurons, represented by low-threshold, IF-EYFP neurons, with strongly fluorescent beaded corneal axons, remained relatively stable. Electrophysiologically, cell bodies of both IF- and WF$\mathrm{TRPM}^{+}$neurons of 24-month-old mice maintained the correspondence between amplitude of cold-induced depolarization and somatic fluorescence intensity seen in young animals. Moreover, they exhibit responses to cooling and menthol very similar to those shown by the corresponding neuron types of young mice, with the sole difference of a weaker response of old IF neurons to menthol. The change in the proportion of neurons with different fluorescence intensity may reflect a phenotypic change in the expression of TRPM8 by TG neurons, in parallel or combined with a higher vulnerability of IF $\mathrm{TRPM}^{+}$neurons to aging.

In contrast with the relatively discrete changes observed in cell bodies, the morphological and functional characteristics of corneal TRPM8-EYFP axons and terminals appeared markedly altered in aged mice. The total density of subbasal corneal TRPM8-EYFP axons was significantly lower, primarily at the expenses of a very large reduction of TRPM8-EYFP beaded axons, which was partially compensated by an increased density of TRPM8-EYFP axons with smooth, thin axons. HBLT cold-sensitive endings were still present in aged animals but generally exhibited a lower background activity and weaker responses to cooling. We interpret these changes as caused by the sharp reduction with aging of the characteristic complex branching associated to cold thermoreceptors (Ivanusic et al., 2013) leading to a smaller membrane area available for the generation of cold-induced depolarization at the terminals branches where TRPM8 channels are located (Brock et al., 2001; Carr et al., 2009; Olivares et al., 2015). In young adult mice, we attribute the distinct firing characteristics of LB-HT cold terminals to a comparatively low-TRPM8 channel density. The presence in old animals of a larger number of this type of neurons and terminals supports the tenet that they correspond to functionally impaired axons that give rise to sparser terminal branching.

Altogether, our data indicate that the morphological and functional consequences of aging appear earlier in the peripheral branches than in the soma of cold sensory neurons and vary depending on the functional subtype of neuron. Such differential effects of senescence on the distinct subclasses of sensory neurons are not entirely surprising. In other somatosensory and visceral tissues of rodents and humans, ageinduced cellular and molecular changes are not reflected in simultaneous and general disturbances of all modalities of sensory innervation (Fundin et al., 1997; Namer et al., 2009; Nolano et al., 2013).

The morphological and functional modifications of corneal coldsensitive innervation with age are part of the general, senescenceinduced degenerative processes affecting primary sensory neurons, associated with DNA damage and oxidative stress (for review see Long et al., 2014). These changes are likely reflected in morphometric, ultrastructural, and functional alterations of peripheral axons that, in the case of peripheral corneal nerves, may be accelerated by the slowdown 
in regeneration and remodeling of the nerve terminals that are needed to maintain the innervation of the rapidly turning over surface layers of the corneal epithelium.

\section{3 | Role of TRPM8-expressing endings in the altered basal tearing of aged mice}

There is growing evidence that modulation of basal tearing involves TRPM $^{+}$cold fibers activated by evaporation-induced temperature and osmolality changes of the tear film (Belmonte et al., 2015, 2017). Notably, an enhancement of tearing rate developed in mice when aging progressed; tear osmolarity was also slightly higher, in spite of the augmented aqueous tear flow. Paradoxically, this effect appears in parallel with a reduction in density of beaded, IF subbasal axons, whose tonic activity is expected to maintain the basal tearing of young animals (Parra et al., 2010). However, such decline in density is accompanied by an increase of WF axons and endings phenotypically associated with polymodal nociceptors, whose abnormal ongoing and cold-evoked activity could explain an irritative, augmented tear flow.

In old people diagnosed with DED, an increased tearing (epiphora) accompanying irritation and discomfort is often observed. Discomfort sensations and augmented tearing are experimentally evoked in humans by selective, strong cold receptor stimulation (Acosta et al., 2004; Kovács et al., 2016). Although epiphora in elderly people has been primarily attributed to partial or complete occlusion of the tear drainage pathways (Sousa et al., 1993), it is possible that in these patients, as in aged mice, abnormal activity of functionally impaired cold-sensitive neurons contribute to the overflow of tears. In these subjects, it is also possible that sensory signaling by cold-sensitive fibers connected to nociceptive pathways produce the unpleasant "dry eye" sensations paradoxically reported by epiphora patients.

Taken together, our study shows that aging causes a reduction of the number and functional activity of canonical low-threshold cold receptor neurons of the eye surface which contribute to maintenance tonic basal tearing and also provokes a disturbed responsiveness of high-threshold cold thermoreceptor neurons, making some of them sensitive to moderate cooling, thereby favoring the appearance of unpleasant ocular dryness sensations and irritative tearing. The disturbed equilibrium between TRPM8-expressing endings ultimately determine the changes in the quality and amount of tears observed in aged DED patients and the development of accompanying unpleasant dryness sensations.

\section{ACKNOWLEDGMENTS}

This work was supported by grants FC-15-GRUPIN14-141 (Consejería de Economía y Empleo, Asturias, Spain), Fundación Ramón Areces, Caja Rural de Asturias, SAF2014-54518-C3-2-R, SAF201454518-C3-1-R, SAF2017-83674-C2-2-R, SAF2017-83674-C2-1-R, and SAF2016-77233-R (Ministerio de Economía, Industria y Competitividad, Spain and European Regional Development Funds, European Union), and "Severo Ochoa" Program for Centers of Excellence in R\&D (SEV-2013-0317). Authors thank Dr. James Brock for critical reading of the manuscript and Paola Braga for technical assistance.

\section{CONFLICT OF INTEREST}

The authors have no conflicts of interest.

\section{ORCID}

Ignacio Alcalde (iD http://orcid.org/0000-0001-6051-9240

Almudena Íñigo-Portugués (iD https://orcid.org/0000-0003-4368-5495

Juana Gallar (iD https://orcid.org/0000-0002-3559-3649

Félix Viana (D) https://orcid.org/0000-0003-1439-949X

Jesús Merayo-Lloves (DD https://orcid.org/0000-0001-8168-478X

Carlos Belmonte (D) http://orcid.org/0000-0001-6891-5942

\section{REFERENCES}

Abe, J., Hosokawa, H., Okazawa, M., Kandachi, M., Sawada, Y., Yamanaka, K., ... Kobayashi, S. (2005). TRPM8 protein localization in trigeminal ganglion and taste papillae. Molecular Brain Research, 136(12), 91-98.

Acosta, M. C., Alfaro, M. L., Borras, F., Belmonte, C., \& Gallar, J. (2006). Influence of age, gender and iris color on mechanical and chemical sensitivity of the cornea and conjunctiva. Experimental Eye Research, 83(4), 932-938.

Acosta, M. C., Peral, A., Luna, C., Pintor, J., Belmonte, C., \& Gallar, J. (2004). Tear secretion induced by selective stimulation of corneal and conjunctival sensory nerve fibers. Investigative Ophthalmology \& Visual Science, 45(7), 2333-2336.

Alamri, A., Bron, R., Brock, J. A., \& Ivanusic, J. J. (2015). Transient receptor potential cation channel subfamily $\mathrm{V}$ member 1 expressing corneal sensory neurons can be subdivided into at least three subpopulations. Frontiers in Neuroanatomy, 9, 71.

Babes, A., Zorzon, D., \& Reid, G. (2004). Two populations of coldsensitive neurons in rat dorsal root ganglia and their modulation by nerve growth factor. European Journal of Neuroscience, 20(9), 22762282.

Belmonte, C., Acosta, M. C., Merayo-Lloves, J., \& Gallar, J. (2015). What causes eye pain? Current Ophthalmology Reports, 3(2), 111-121.

Belmonte, C., \& Gallar, J. (2011). Cold thermoreceptors, unexpected players in tear production and ocular dryness sensations. Investigative Ophthalmology \& Visual Science , 52(6), 3888-3892.

Belmonte, C., Nichols, J. J., Cox, S. M., Brock, J. A., Begley, C. G., Bereiter, D. A., ... Wolffsohn, J. S. (2017). TFOS DEWS II pain and sensation report. Ocular Surface, 15(3), 404-437.

Bergman, E., \& Ulfhake, B. (1998). Loss of primary sensory neurons in the very old rat: Neuron number estimates using the disector method and confocal optical sectioning. Journal of Comparative Neurology, $396(2), 211-222$

Brock, J. A., McLachlan, E. M., \& Belmonte, C. (1998). Tetrodotoxinresistant impulses in single nociceptor nerve terminals in guinea-pig cornea. Journal of Physiology, 512(Pt 1), 211-217.

Brock, J. A., Pianova, S., \& Belmonte, C. (2001). Differences between nerve ending impulses of polymodal nociceptors and cold sensory receptors of the guinea-pig cornea. Journal of Physiology, 533(Pt 2), 493-501.

Carr, R. W., Pianova, S., McKemy, D. D., \& Brock, J. A. (2009). Action potential initiation in the peripheral endings of cold-sensitive 
neurones innervating the guinea-pig cornea. Journal of Physiology, 587(Pt 6), 1249-1264.

Comfort, A. (1964). Aging: The biology of senescence. New York, NY: Holt, Rinehart and Winston.

Craig, J. P., Nelson, J. D., Azar, D. T., Belmonte, C., Bron, A. J., Chauhan, S. K., ... Sullivan, D. A. (2017). TFOS DEWS II report executive summary. Ocular Surface, 15(4), 802-812.

de la Peña, E., Malkia, A., Cabedo, H., Belmonte, C., \& Viana, F. (2005). The contribution of TRPM8 channels to cold sensing in mammalian neurones. Journal of Physiology, 567(Pt 2), 415-426.

Dvorscak, L., \& Marfurt, C. F. (2008). Age-related changes in rat corneal epithelial nerve density. Investigative Ophthalmology \& Visual Science, 49(3), 910-916.

Fundin, B. T., Bergman, E., \& Ulfhake, B. (1997). Alterations in mystacial pad innervation in the aged rat. Experimental Brain Research, 117(2), 324-340.

Furukawa, R. E., \& Polse, K. A. (1978). Changes in tear flow accompanying aging. American Journal of Optometry and Physiological Optics, 55 (2), 69-74.

Gallar, J., Pozo, M. A., Tuckett, R. P., \& Belmonte, C. (1993). Response of sensory units with unmyelinated fibres to mechanical, thermal and chemical stimulation of the cat's cornea. Journal of Physiology, 468, 609-622.

Gipson, I. K. (2013). Age-related changes and diseases of the ocular surface and cornea. Investigative Opthalmology \& Visual Science, 54(14), ORSF48-ORSF53.

González-González, O., Bech, F., Gallar, J., Merayo-Lloves, J., \& Belmonte, C. (2017). Functional properties of sensory nerve terminals of the mouse cornea. Investigative Opthalmology \& Visual Science, 58(1), 404-415.

He, J., Bazan, N. G., \& Bazan, H. E. (2010). Mapping the entire human corneal nerve architecture. Experimental Eye Research, 91(4), 513-523.

Hirata, H., \& Meng, I. D. (2010). Cold-sensitive corneal afferents respond to a variety of ocular stimuli central to tear production: Implications for dry eye disease. Investigative Ophthalmology \& Visual Science, 51 (8), 3969-3976.

Hirata, H., \& Oshinsky, M. L. (2012). Ocular dryness excites two classes of corneal afferent neurons implicated in basal tearing in rats: Involvement of transient receptor potential channels. Journal of Neurophysiology, 107(4), 1199-1209.

Ivanusic, J. J., Wood, R. J., \& Brock, J. A. (2013). Sensory and sympathetic innervation of the mouse and guinea pig corneal epithelium. Journal of Comparative Neurology, 521(4), 877-893.

Knowlton, W. M., Palkar, R., Lippoldt, E. K., McCoy, D. D., Baluch, F., Chen, J., \& McKemy, D. D. (2013). A sensory-labeled line for cold: TRPM8-expressing sensory neurons define the cellular basis for cold, cold pain, and cooling-mediated analgesia. Journal of Neuroscience: Official Journal of the Society for Neuroscience, 33(7), 2837-2848.

Kovács, I., Luna, C., Quirce, S., Mizerska, K., Callejo, G., Riestra, A., ... Gallar, J. (2016). Abnormal activity of corneal cold thermoreceptors underlies the unpleasant sensations in dry eye disease. Pain, 157(2), 399-417.

Lamberts, D. W., Foster, C. S., \& Perry, H. D. (1979). Schirmer test after topical anesthesia and the tear meniscus height in normal eyes. Archives of Ophthalmology, 97(6), 1082-1085.

Long, Y. C., Tan, T. M., Takao, I., \& Tang, B. L. (2014). The biochemistry and cell biology of aging: Metabolic regulation through mitochondrial signaling. American Journal of Physiology Endocrinology and Metabolism, 306(6), E581-E591.

Madrid, R., de la Peña, E., Donovan-Rodriguez, T., Belmonte, C., \& Viana, F. (2009). Variable threshold of trigeminal cold-thermosensitive neurons is determined by a balance between TRPM8 and Kv1 potassium channels. Journal of Neuroscience, 29(10), 3120-3131.
Madrid, R., Donovan-Rodríguez, T., Meseguer, V., Acosta, M. C., Belmonte, C., \& Viana, F. (2006). Contribution of TRPM8 channels to cold transduction in primary sensory neurons and peripheral nerve terminals. Journal of Neuroscience: Official Journal of the Society for Neuroscience, 26(48), 12512-12525.

Marfurt, D. F., Cox, J., Deek, S., \& Dvorscak, L. (2010). Anatomy of the human corneal innervation. Experimental Eye Research, 90(4), 478-492.

McKemy, D. D., Neuhausser, W. M., \& Julius, D. (2002). Identification of a cold receptor reveals a general role for TRP channels in thermosensation. Nature, 416(6876), 52-58.

Meng, I. D., \& Kurose, M. (2013). The role of corneal afferent neurons in regulating tears under normal and dry eye conditions. Experimental Eye Research, 117, 79-87.

Morenilla-Palao, C., Luis, E., Fernandez-Pena, C., Quintero, E., Weaver, J. L., Bayliss, D. A., \& Viana, F. (2014). Ion channel profile of TRPM8 cold receptors reveals a role of TASK- 3 potassium channels in thermosensation. Cell Reports, 8(5), 1571-1582.

Namer, B., Barta, B., Orstavik, K., Schmidt, R., Carr, R., Schmelz, M., \& Handwerker, H. O. (2009). Microneurographic assessment of C-fibre function in aged healthy subjects. Journal of Physiology, 587(2), 419-428.

Nolano, M., Provitera, V., Caporaso, G., Stancanelli, A., Leandri, M., Biasiotta, A., ... Truini, A. (2013). Cutaneous innervation of the human face as assessed by skin biopsy. Journal of Anatomy, 222(2), 161-169.

Olivares, E., Salgado, S., Maidana, J. P., Herrera, G., Campos, M., Madrid, R., \& Orio, P. (2015). TRPM8-dependent dynamic response in a mathematical model of cold thermoreceptor. PLoS One, 10, e0139314.

Palkar, R., Lippoldt, E. K., \& McKemy, D. D. (2015). The molecular and cellular basis of thermosensation in mammals. Current Opinion in Neurobiology, 34, 14-19.

Parissi, M., Karanis, G., Randjelovic, S., Germundsson, J., Poletti, E., Ruggeri, A., ... Lagali, N. (2013). Standardized baseline human corneal subbasal nerve density for clinical investigations with laser-scanning in vivo confocal microscopy. Investigative Ophthalmology \& Visual Science, 54(10), 7091-7102.

Parra, A., Madrid, R., Echevarria, D., del Olmo, S., Morenilla-Palao, C., Acosta, M. C., ... Belmonte, C. (2010). Ocular surface wetness is regulated by TRPM8-dependent cold thermoreceptors of the cornea. Nature Medicine, 16(12), 1396-1399.

Peier, A. M., Moqrich, A., Hergarden, A. C., Reeve, A. J., Andersson, D. A., Story, G. M., ... Patapoutian, A. (2002). A TRP channel that senses cold stimuli and menthol. Cell, 108(5), 705-715.

Quallo, T., Vastani, N., Horridge, E., Gentry, C., Parra, A., Moss, S., .. Bevan, S. (2015). TRPM8 is a neuronal osmosensor that regulates eye blinking in mice. Nature Communications, 6, 7150.

Reichard, M., Weiss, H., Poletti, E., Ruggeri, A., Guthoff, R. F., Stachs, O., \& Baltrusch, S. (2016). Age-related changes in murine corneal nerves. Current Eye Research, 41(8), 1021-1028.

Robbins, A., Kurose, M., Winterson, B. J., \& Meng, I. D. (2012). Menthol activation of corneal cool cells induces TRPM8-mediated lacrimation but not nociceptive responses in rodents. Investigative Opthalmology \& Visual Science, 53(11), 7034-7042.

Stern, M. E., Gao, J., Siemasko, K. F., Beuerman, R. W., \& Pflugfelder, S. C. (2004). The role of the lacrimal functional unit in the pathophysiology of dry eye. Experimental Eye Research, 78(3), 409-416.

Sousa, P. C., Pinto, P., Leite, E., \& Cunha-Vaz, J. G. (1993). Morphological and/or functional imagiology diagnosis of epiphora. Documenta Ophthalmologica. Advances in Ophthalmology, 83(4), 337-348.

Takashima, Y., Daniels, R. L., Knowlton, W., Teng, J., Liman, E. R., \& McKemy, D. D. (2007). Diversity in the neural circuitry of cold sensing revealed by genetic axonal labeling of transient receptor potential 
melastatin 8 neurons. Journal of Neuroscience: Official Journal of the Society for Neuroscience, 27(51), 14147-14157.

Teichert, R. W., Raghuraman, S., Memon, T., Cox, J. L., Foulkes, T., Rivier, J. E., \& Olivera, B. M. (2012). Characterization of two neuronal subclasses through constellation pharmacology. Proceedings of the National Academy of Science USA, 109(31), 12758-12763.

Viana, F., de la Pena, E., \& Belmonte, C. (2002). Specificity of cold thermotransduction is determined by differential ionic channel expression. Nature Neuroscience, 5(3), 254-260.

Wang, S., \& Albers, K. M. (2009). Behavioral and cellular level changes in the aging somatosensory system. Annals of the New York Academy of Sciences, 1170, 745-749.
Xing, H., Ling, J., Chen, M., \& Gu, J. G. (2006). Chemical and cold sensitivity of two distinct populations of TRPM8-expressing somatosensory neurons. Journal of Neurophysiology, 95(2), 1221-1230.

How to cite this article: Alcalde I, Íñigo-Portugués A, GonzálezGonzález $\mathrm{O}$, et al. Morphological and functional changes in TRPM8-expressing corneal cold thermoreceptor neurons during aging and their impact on tearing in mice. J Comp Neurol. 2018;526:1859-1874. https://doi.org/10.1002/cne.24454 